\title{
Variaciones recientes de glaciares en Chile
}

\author{
Andrés Rivera \\ Departamento de Geografía, Universidad de Chile, arivera@abello.dic.uchile.cl \\ Gino Casassa \\ Instituto de la Patagonia, Universidad de Magallanes, gcasassa@yagan.fh.umag.cl \\ César Acuña \\ Laboratorio de Glaciología, Universidad de Chile \\ $\mathrm{y}$ \\ Heiner Lange \\ Terrasat S.A.
}

\begin{abstract}
RESUMEN
Se presenta una síntesis de la investigación glaciológica realizada en Chile durante las últimas décadas, incluyendo los inventarios existentes, los balances de masa y las variaciones de glaciares, todo lo cual se analiza con relación a los cambios climáticos que han afectado el país. En Chile se han medido variaciones frontales históricas para casi 100 glaciares, que representan el 5,6\% del total de glaciares inventariados hasta ahora en el país. De ellos, sólo el $6 \%$ ha presentado un estado neto de avance en los períodos estudiados, destacando el del glaciar Pío XI con un promedio de $+206 \mathrm{~m}$ a-1 para el período 1945-1997. Un $7 \%$ de los glaciares estudiados no han experimentado un cambio significativo, mientras que cerca de un $87 \%$, han tenido tasas de variación negativas, desde pocos metros por año, hasta un máximo de $-278 \mathrm{~m}$ a-1 en el glaciar Amalia para el período 1945-1986.

No obstante existir comportamientos de glaciares que obedecen a factores no climáticos, se confirma que la mayoría de las fluctuaciones de los glaciares son generadas por los aumentos de temperatura detectados en numerosas estaciones de Chile, algunas de las cuales muestran para las últimas tres décadas, aumentos de casi el doble de la tendencia secular. También han incidido significativamente en las variaciones de los glaciares, los ciclos interanuales con anomalías pluviométricas extremas y la tendencia de algunas estaciones que han experimentado un descenso de los montos totales anuales de precipitación. Finalmente, la mayor frecuencia de fenómenos El Niño / Oscilación del Sur (ENOS), han tenido un rol significativo en la variabilidad interanual de las precipitaciones y temperaturas, generando respuestas distintas a nivel regional.

Frente a dichas tendencias climáticas, se espera que el retroceso de glaciares continúe, que los balances de masa mantengan sus tendencias negativas y que los adelgazamientos aumenten, todo lo cual impactará la dotación y disponibilidad de recursos hídricos en el país.
\end{abstract}

Palabras claves: Glaciares, cambio climático, ENOS, balance de masa.

\section{Recent glacier variations in Chile}

\begin{abstract}
A synthesis of glaciological research carried out in Chile during the last decades is presented, including existing inventories, mass balance and glacier variations, which are related to the regional climate change. In Chile, almost 100 glaciers have been measured in terms of their historical frontal variations. They represent $5,6 \%$ of the total inventoried glaciers of the country. Only $6 \%$ of the inventoried glaciers show a net advance during the study period, especially glaciar Pío XI with an average of $206 \mathrm{~m}$ a-1 between 1945-1997. A $7 \%$ of the studied glaciers show no significant change, while $87 \%$ show a negative rate of variation, ranging from a few meters per year to a maximum of $278 \mathrm{~m}$ a- 1 at glaciar Amalia for the period 1945-1986.

Although there are some glaciers with variations related to non-climatic effects, most of the glacier variations are driven by the temperature increase which has been detected in several stations of Chile. Some of these stations show a doubling of the warming rate during the last three decades compared to the secular trend. Anomalies of rainfall and the decreasing trend in the annual precipitation shown in a few stations, have also affected significantly the glacier variations. Finally, the higher frequency of El Niño/Southern Oscillation phenomena (ENSO), has had a significant influence on the inter-annual variability of the precipitation and temperature, with a contrasting response of glaciers at a regional level.

Based on observed climatic trends, it is expected that the glacier retreat will continue, the mass balance will maintain negative trends and the thinning rates will increase, affecting the availability of water resources of the country in the future.
\end{abstract}

Keywords: Glaciers, climate change, ENSO, mass balance. 


\section{INTRODUCCION}

Uno de los efectos más importantes del calentamiento global, es el aumento del nivel del mar generado por la fusión de los glaciares de montaña. MEIER (1984) estimó que, entre 1900 y 1961, la contribución de los glaciares de montaña (excluidos Antártica y Groenlandia), al aumento global del nivel del mar alcanzó $0.46 \mathrm{~mm} \mathrm{a-1,} \mathrm{de} \mathrm{los} \mathrm{cuales} \mathrm{los}$ glaciares de los Andes, entre los $30^{\circ}$ y $55^{\circ} \mathrm{S}$, contribuirían con el $11.6 \%$.

Para dichos cálculos se estimó que la superficie de glaciares en los Andes (30-55 $\mathrm{S}$ ) era de $31,000 \mathrm{~km} 2$, lo que equivale al $5.7 \%$ del total mundial. Sin embargo, los datos actuales para esta área de los Andes chilenos, incluidos el Campo de Hielo Norte (CHN) y la totalidad del Campo de Hielo Sur (CHS), llegaría sólo a 22,066 km2 de hielo. Esto implica que, de acuerdo a MEIER, en los Andes argentinos al norte del CHS habrían ca. $9,000 \mathrm{~km} 2$ de hielo, lo que parece exagerado a la luz de los inventarios de glaciares existentes en Argentina central $\left(29-35^{\circ} \mathrm{S}\right)$, donde sólo habrían 1,343 $\mathrm{km} 2$ de hielo (ESPIZÚA y AGUADO 1984).

Analizando el CHN y el CHS, ANIYA (1999) estimó que los aportes al aumento del nivel medio del mar de esta zona, alcanzarían a 0.038 mm a-1, lo que representa un $8,3 \%$ del total estimado por MEIER. Considerando que la superficie empleada por ANIYA en los Campos de Hielo Patagónicos (Fig. 1), sólo representa el $2.85 \%$ del total de los pequeños glaciares del planeta, es evidente que su aporte es desproporcionadamente alto, lo que indicaría que la fusión de glaciares en Patagonia ha sido más rápida que en otras zonas.

En el resto del país, los pocos glaciares estudiados también muestran una clara tendencia de retroceso de sus lenguas terminales, pero se desconocen los volúmenes aportados al incremento del nivel del mar, debido a la falta de datos. En efecto, aún no se completa el inventario de glaciares del país, existe sólo un registro de balance de masa (glaciar Echaurren en Fig. 1), hay escasas mediciones de espesor de hielo y se han medido muy pocos cambios de superficies glaciares (CASASSA et al.1998a).

\section{MATERIALES Y METODOS}

Este artículo presenta nuevos y numerosas datos sobre los glaciares del país, con el objetivo principal de recopilar y sintetizar la información glaciológica existente, por lo que el análisis detallado de los materiales y métodos empleados en las investigaciones realizadas en el país escapa de este enfoque y requeriría una publicación especial.

No obstante lo anterior, a continuación se detallan los principales materiales y métodos empleados para la elaboración de este trabajo.

\section{Variaciones frontales $\mathbf{y}$ areales}

Para determinar las variaciones frontales y areales de glaciares, se han empleado principalmente fotografias aéreas, donde se han dibujado las características glaciares, siendo traspasada dicha información por medio del instrumento óptico Zoom Transfer Scope a cartografía regular del IGM. También se han empleado imágenes de satélite, las que han sido georeferenciadas sobre la cartografia regular de formato digital. Otra fuente de información ha sido la histórica, puesto que hay numerosas descripciones de frentes glaciares en crónicas de viajes o exploraciones, las que han sido mapeadas y relacionadas con parámetros topográficos actuales.

En algunas ocasiones, se han posicionado los frentes glaciares con visitas a terreno y análisis de cartografia existente.

\section{Velocidades}

Entre los principales métodos de medición de velocidades, está el taquimétrico, que permite medir el movimiento de balizas o seracs de la lengua glaciar en el lapso de algunos días, mediante un teodolito ubicado en el margen rocoso; el fotogramétrico, que permite evaluar iguales elementos presentes sobre la lengua glaciar en fotos aéreas de distintas fechas; método de separación de ojivas, bandas de hielo claro y oscuro de carácter anual que se extienden en la superficie de algunos glaciares, por debajo de cascadas de hielo; y método interferométrico, que permite medir velocidades al comparar dos imágenes de satélite de radar tomadas con escasa separación de tiempo, desde una misma línea base (PATERSON 1994; 
RIGNOT et al. 1996a).

\section{Espesores}

Las mediciones de espesor de hielo realizadas en Chile, han sido llevadas a cabo con métodos gravimétricos y de radar.

El método gravimétrico permite determinar el espesor del hielo a partir de la deficiencia de la componente vertical de la aceleración de gravedad observada sobre un glaciar. Esta deficiencia se origina debido a la menor densidad del hielo $(0.9 \mathrm{gr} / \mathrm{cm} 3)$ con respecto a la roca subyacente (aproximadamente $2.7 \mathrm{gr} /$ $\mathrm{cm} 3$ ).

Para convertir valores de gravedad observada a espesores de hielo, es necesario en primer lugar llevar todos estos valores a un plano de referencia común, generalmente el nivel medio del mar, obteniendo de esta manera anomalías de gravedad, o anomalías "de Bouguer" sobre el hielo. Al mismo tiempo, es preciso medir la gravedad en los afloramientos de roca aledaños al glaciar, determinando la anomalía regional de Bouguer. La diferencia de las anomalías de Bouguer entre la roca y el hielo resultan en anomalías residuales debidas al hielo, a partir de las cuales se aplica un modelo, o método inverso para evaluar el espesor del glaciar que origina tales anomalías.

Las ventajas del método gravimétrico son sus facilidades logísticas y su capacidad de penetración virtualmente ilimitada para determinar espesores de hielo. Sin embargo, este método es limitado en cuanto a su precisión, debido al hecho de que se mide un valor promedio de gravedad bajo la estación, que suaviza y subestima en forma importante el espesor máximo del hielo, especialmente en zonas con complejo relieve subglacial (DREWRY 1975).

El método de radio eco sondaje (radar), consiste en transmitir una señal hacia el interior del glaciar, la que rebota en la base rocosa y es captada por un receptor instalado en la superficie.

El espesor se determina a partir del tiempo que demora la onda electromagnética transmitida, que penetra el hielo y rebotando en el fondo rocoso, llega al receptor con un retraso de algunos microsegundos, dependiendo del espesor penetrado.

Cuando se mide hielo temperado con agua de fusión a nivel intraglacial, hay una importante reflexión intraglacial de las señales, conocida como dispersión, por lo que se debe emplear un sistema de radar que trabaja a frecuencias inferiores a $10 \mathrm{MHz}$, lo que se contrapone a las frecuencias típicamente empleadas en hielos fríos que son superiores a $30 \mathrm{MHz}$.

Asimismo, pueden existir reflexiones internas importantes debido a estratos internos depositados por actividad volcánica reciente y a la presencia de numerosas morrenas mediales y laterales (RIVERA et al. 1998a), lo que también puede oscurecer el retorno, o reflexión del fondo del glaciar.

Este sistema de radar de baja frecuencia, ha sido empleado con éxito en varios glaciares de Campo de Hielo Sur, Antártica y Chile Central, existiendo sólo mínimas diferencias en los equipos utilizados y el sistema de medición.

Uno de los primeros sistemas empleados, consistía en un transmisor de 2 a $5 \mathrm{MHz}$ y un osciloscopio análogo, cuya pantalla debía ser fotografiada para capturar la señal (CASASSA 1992)

Para reducir los problemas técnicos que implicaba fotografiar la pantalla del receptor, se diseñó un segundo sistema de radar, compuesto por un transmisor de $5 \mathrm{MHz}$ y un osciloscopio digital, que permitía el traspaso de las señales a PC, el cual se conectaba directamente al receptor (CASASSA and RIVERA 1998).

En la actualidad, se sigue empleando este sistema, pero las antenas son amarradas a cañas de fibra de vidrio de $8 \mathrm{~m}$ de largo, las que son adosadas a mochilas que son porteadas por los investigadores, permitiéndose la colección de datos en forma continua al caminar con este sistema sobre el hielo.

Para mediciones de espesor de hielo con radar en grandes superficies, se ha diseñado un sistema de perfilaje, que permite obtener un dato de espesor cada dos segundos, generando un perfil continuo de retornos subglaciales (CASASSA et al. 1998b).

En este sistema de perfilaje, el transmisor y el 


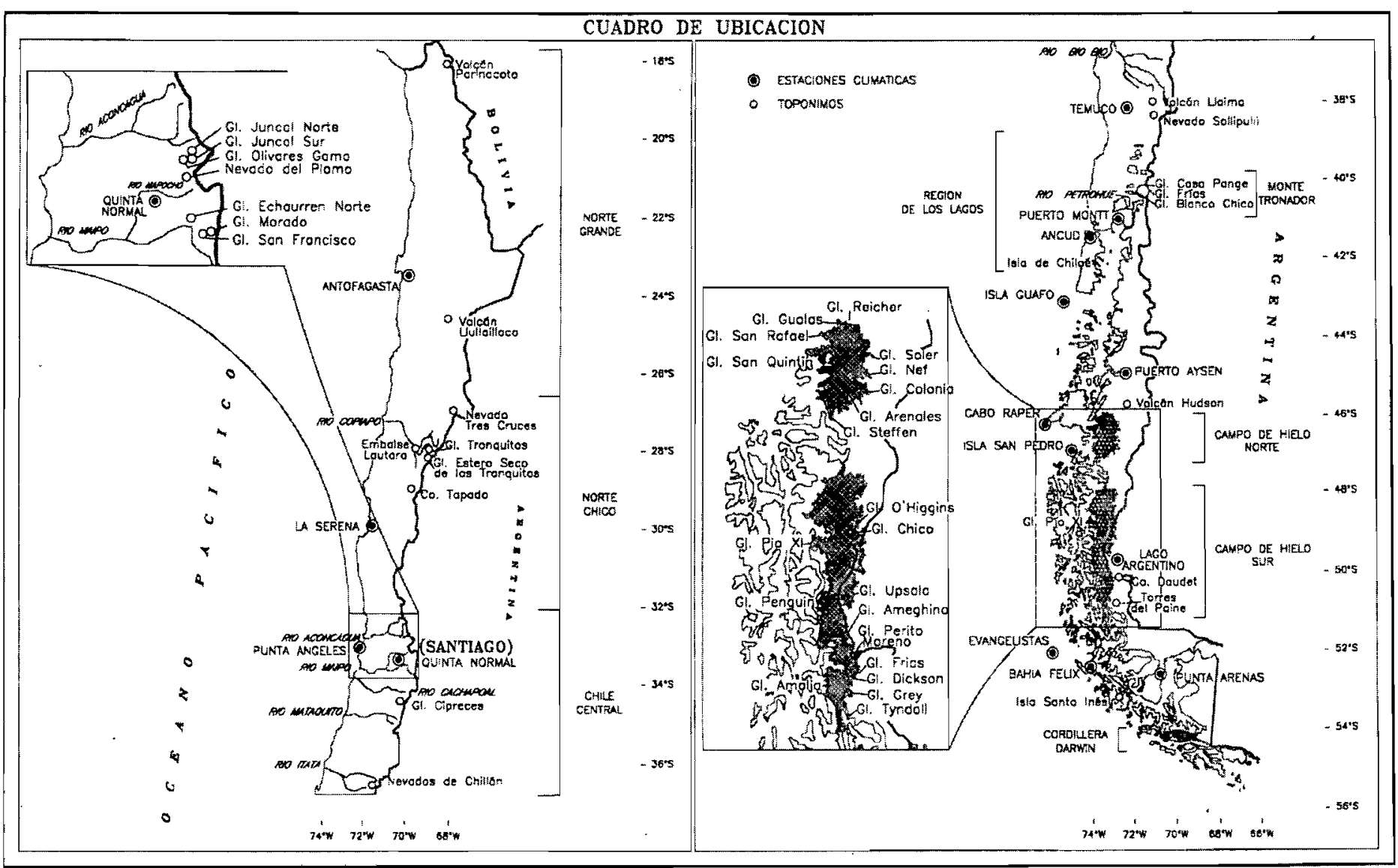

Fig.1. Cuadro de ubicación de estaciones y toponimia empleada en el texto. Fig. 1. Toponymy and location of the stations used in the text. 
FIgURA 2

\section{INVENTARIOS DE GLACIARES EN CHILE}

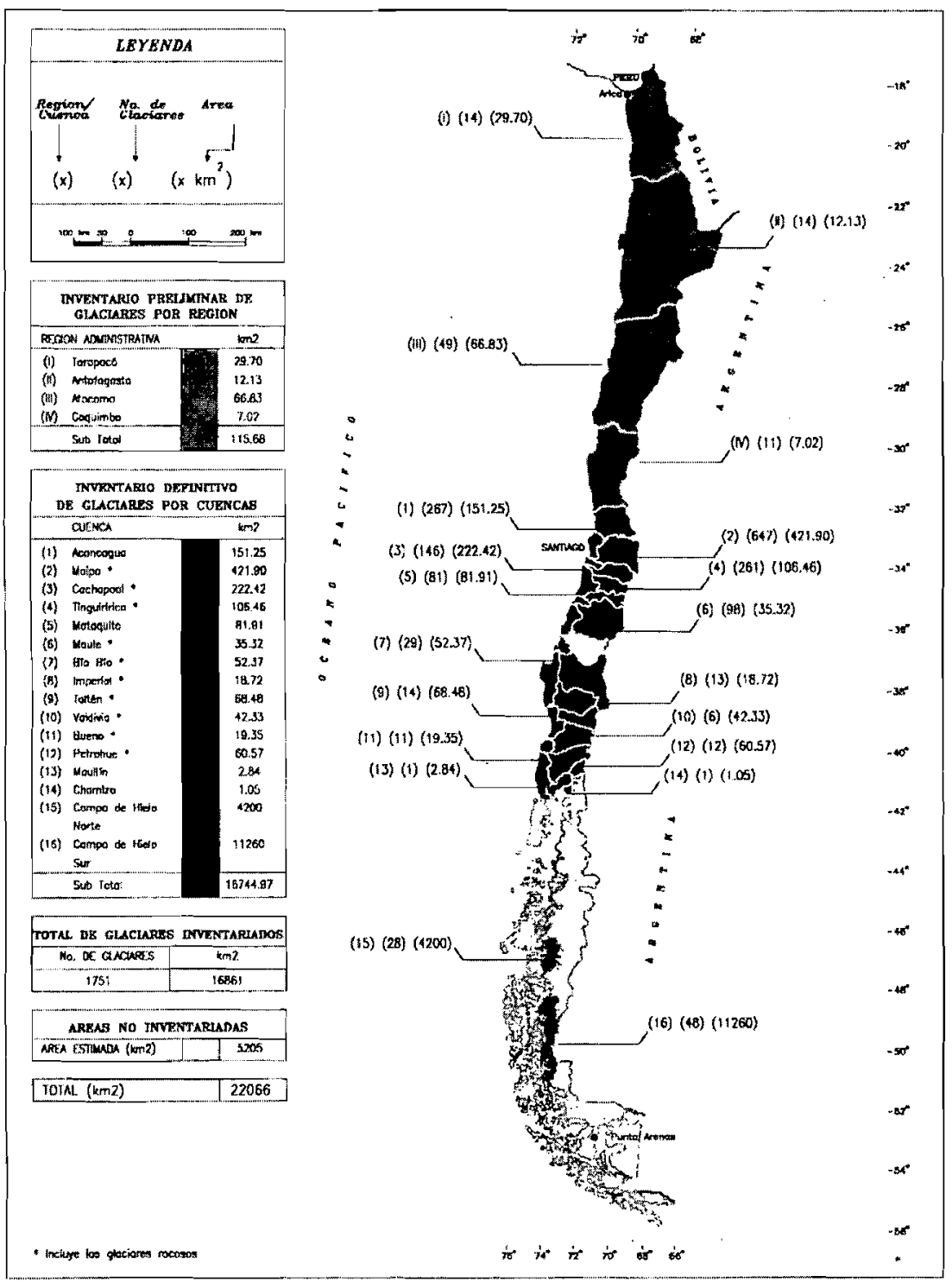

Fig. 2. Inventario de glaciares de Chile.

Fig. 2. Glacier Inventory of Chile. 
receptor están montados sobre trineos, que son impulsados por un mototobogán. Se utilizan antenas con longitud de medio dipolo de 20 metros, dispuestas en línea y con un largo total del sistema de radar de 120 metros. El trineo receptor está a 40 metros del mototobogán, y el trineo del transmisor, 100 metros atrás del mototobogán. Por lo tanto, la separación entre transmisor y receptor es de 60 metros.

Entre los transmisores empleados, se cuenta el OSU, diseñado por The Ohio State University (EE.UU.), siendo alimentado por una batería de $12 \mathrm{~V}$, generando un monopulso de $1600 \mathrm{Vpp}$. El transmisor se conecta directamente a una antena dipolo cargada resistivamente, con una longitud de medio dipolo de 20 metros, lo cual se traduce en una frecuencia de $2.5 \mathrm{MHz}$ en aire. El transmisor y su batería se instalan en un trineo de fibra de vidrio de 2.1 metros de largo.

En el receptor, las antenas se conectan vía balun a un osciloscopio digital Tektronics modelo TekScope THS 720, con un ancho de banda de $100 \mathrm{MHz}$. Los datos son almacenados en el

TABLA 1

Inventario de Glaciares en Chile

\begin{tabular}{|c|c|c|c|c|c|}
\hline $\begin{array}{l}\text { Región } \\
\text { administrativa }\end{array}$ & Cuenca hidrográfica & $\begin{array}{c}N^{\circ} \text { de } \\
\text { glaciares }\end{array}$ & Area en $\mathrm{km}^{2}$ & $\begin{array}{c}\% \text { de } \\
\text { superficie con } \\
\text { glaciares }\end{array}$ & Fuente \\
\hline 1 & • & 14 & 29.70 & rocosos & GARIN (1987) \\
\hline$\|$ & $\cdot$ & 14 & 12.13 & sii & GARIN (1987) \\
\hline III & . & 49 & 66.83 & siti & GARIN (1987) \\
\hline IV & $\cdot$ & 11 & $7.02^{\text {t+ }}$ & síi & GARÍN (1987) \\
\hline V & Aconcagua & 267 & 151.25 & sii & VALDIVIA (1984) \\
\hline Metropolitana & Maipo & 647 & 421.9 & sii & MARANGUNIC (1979) \\
\hline VI & Cachapoal & 146 & 222.42 & $39 \% * *$ & CAVIEDES $(1979)$ \\
\hline VI & Tinguiririca & 261 & 106.46 & $21 \%$ & VALDIVIA (1984) \\
\hline VII & Mataquito & 81 & 81.91 & $3 \%$ & NOVEROY $(1987\}$ \\
\hline VIII & Maule & 98 & 35.32 & $\begin{array}{c}\text { sil } \\
20 \%\end{array}$ & $\begin{array}{l}\text { Comunicación personal } \\
\text { G. Tapia (DGA) }\end{array}$ \\
\hline$V|I|-I X$ & Bío Bío & 29 & 52.37 & & RIVERA (1989) \\
\hline IX & Imperial & 13 & 18.72 & $2 \%$ & RIVERA (1989) \\
\hline $\mid x-x$ & Toltén & 14 & 68.48 & $26 \%$ & RIVERA (1989) \\
\hline $1 x-x$ & Valdivia & 6 & 42.33 & $21 \%$ & RIVERA (1989) \\
\hline$x$ & Bueno & 11 & 19.35 & $25 \%$ & RIVERA (1989) \\
\hline$x$ & Petrohué & 12 & 60.57 & $2 \%$ & RIVERA (1989) \\
\hline$x$ & Maullín & 1 & 2.84 & $11 \%$ & RIVERA (1989) \\
\hline$x$ & Chamiza & 1 & 1.05 & $0 \%$ & RIVERA (1989) \\
\hline $\mathrm{X} \mid$ & Campo de Hielo Norte & 28 & 4,200 & $0 \%$ & ANIYA (1988) \\
\hline$X I-X \|$ & Campo de Hielo Sur & 48 & $11,260^{m+\cdots}$ & $0 \%$ & ANIYA et al. (1996) \\
\hline Inventariados & Total & 1,751 & 16,861 & $0 \%$ & \\
\hline \multirow[t]{2}{*}{ No inventariados } & Area estimada $\left(\mathrm{km}^{2}\right)^{\star \star \star \star k k}$ & & 5,205 & & \\
\hline & Total $\left(\mathrm{km}^{2}\right)$ & & 22,066 & & \\
\hline
\end{tabular}

Notas:

* Se trata de un inventario preliminar, donde los glaciares no están asociados a cuencas hidrográficas

** No incluye superficie de nieve semipermanente de $31 \mathrm{~km}^{2}$ definida por GARÍN, (1987)

*** Denota glaciares de roca y cubiertos por detritos

****: Aproximadamente entre un 8 y un $19 \%$ de esta superficie se ubica en Argentina, de acuerdo al nuevo acuerdo fronterizo de 1998

***** CASASSA (1995) y este trabajo 
disco duro de un computador portátil mediante una conexión vía puerta serial (RS232). Tanto el computador portátil como el osciloscopio son alimentados por una batería de $12 \mathrm{~V}$ de $85 \mathrm{Ah}$. Todo el sistema de recepción está montado sobre un trineo de fibra de vidrio de 2.1 metros de largo.

\section{RESULTADOS}

\section{Inventarios de Glaciares}

En Chile se han inventariado hasta $1999,1,751$ glaciares con una superficie total de $22,066 \mathrm{~km} 2$ (Tabla 1). Estos inventarios han sido encargados principalmente por la Dirección General de Aguas (DGA) y abarcan principalmente el centro del país (Fig. 2).

En las primeras cuatro regiones del norte del país (Norte Grande en Fig. 1), donde el área englaciada es reducida, el inventario fue realizado por GARÍN (1987), gracias a cartografía regular y preliminar del Instituto Geográfico Militar (IGM) más fotos aéreas. En algunos casos se incluyeron glaciaretes y superficies temporales de nieve. Asimismo, los glaciares no fueron asociados a cuencas hidrográficas, por lo que se requieren estudios más detallados.

En el centro del país (Fig. 1) existe una mayor superficie cubierta por hielo, destacando la cuenca del Maipo donde hay más de $420 \mathrm{~km} 2$ de glaciares (Fig. 2). El derretimiento de estos glaciares ha sido de vital importancia para la mantención de caudales en períodos secos de verano, representando el aporte glacial, desde un tercio hasta el $67 \%$ del caudal del río Maipo en meses de sequía, tales como $1968 / 69$ y 1981/ 82 (PEÑA and NAZARALA, 1987).

En Chile central sólo falta inventariar la cuenca del río Itata (Fig. 1 y 2), donde se estima que existen cerca de $15 \mathrm{~km} 2$ de hielo. El resto del país posee inventarios detallados de glaciares descubiertos, pero no de glaciares de roca o glaciares recubiertos con detritos, que en este estudio se denominan glaciares rocosos, los que sólo fueron incluidos en la cuenca del Maipo por MARANGUNIC (1979). Estos glaciares tendrían una especial importancia en el Norte Chico y en la cuenca del Aconcagua (Fig. 1 y 2), tal como ocurre en el lado argentino (CORTE, 1998). El resto de las cuencas de
Chile central tienen importantes porcentajes de glaciares rocosos, generados por derrumbes laterales, incorporación de material morrénico y regeneración de lenguas terminales (VALDIVIA 1984; RIVERA 1989).

Entre las cuencas del Mataquito y Petrohué (Fig. 1 y 2), la superficie de glaciares tiende a disminuir respecto de Chile central, debido a la menor altura de la cordillera andina. Destaca en esta región, el problema de riesgo potencial que presenta la existencia de grandes casquetes de hielo sobre conos volcánicos activos, por la posibilidad de ocurrencia de lahares, tal como los ocurridos en la última erupción del Volcán Llaima (MORENO y FUENTEALBA 1994). También existe una importante superficie de glaciares recubiertos con material volcánico (RIVERA 1989).

Al sur de la cuenca del río Petrohué en la Región de los Lagos (Fig. 1), existen sólo dos inventarios de glaciares, los que fueron realizados para el CHN por ANIYA (1988) y para el CHS por ANIYA et al. (1996). Ambos casquetes poseen en conjunto más de 17,000 $\mathrm{km} 2$ de hielo, convirtiéndose en la masa de hielo más grande del hemisferio sur después de Antártica (NARUSE and ANIYA 1992).

No obstante el avance en el catastro de glaciares experimentado en las últimas décadas, aûn falta por inventariar gran parte del sur del país, especialmente en las regiones de Aysén y Magallanes, donde existen grandes superficies de glaciares (CASASSA 1998a). Por ejemplo en la Cordillera Darwin hay $2,000 \mathrm{~km} 2$ (CASASSA 1995), en la Isla Santa Inés habrían $250 \mathrm{~km} 2$ (LLIBOUTRY 1956) y en el Volcán Hudson hay un gran casquete de hielo, cuyo volumen fue estimado en $2.5 \mathrm{~km} 3$ (NARANJO et al. 1993).

\section{Balances de masa}

En Chile sólo existe un estudio sistemático de balance de masa, el cual es conducido por la Dirección General de Aguas del Ministerio de Obras Públicas, que monitorea desde 1975 el glaciar Echaurren Norte, ubicado en la cuenca superior del río Maipo (Tablas 1 y 2). Este glaciar ha presentado una alta variabilidad interanual en su balance de masa, lo que estaría en estrecha relación con la presencia o ausencia de los fenómenos ENOS (ESCOBAR et al. 
1995), generándose balances de masa positivos en años El Niño y balances negativos en años La Niña.

En términos acumulados, el balance de masa neto del glaciar Echaurren Norte en las últimas 24 temporadas (entre 1975/76 y 1998/99), alcanzó a $-475 \mathrm{~cm}$ eq. de agua, determinando una importante pérdida de masa. Sin embargo, sus balances han pasado por dos tendencias principales:

1.- Desde 1977/78 hasta el año El Niño $1987 /$ 88 , hubo balances acumulados positivos, sólo

TABLA 2

Glactares con Balances de Masa en Sudamérica

\begin{tabular}{|c|c|c|c|c|c|}
\hline Nombre del glaciar & País & $\begin{array}{l}\text { Area } \\
\left(\mathrm{km}^{2}\right)\end{array}$ & Coordenadas & $\begin{array}{l}\text { Inicio de } \\
\text { mediciones }\end{array}$ & Fuente \\
\hline Antizana & Ecuador & 0.35 & $00^{\circ} 29^{\prime} \mathrm{N} / 78^{\circ} 09^{\prime} \mathrm{W}$ & 1995 & 1 \\
\hline Yanamarey & Perú & 1.29 & $09^{\circ} 39^{\prime} \mathrm{S} / 77^{\circ} 16^{\prime} \mathrm{W}$ & 1977 & 2 \\
\hline Uruashraju & Perú & 2.15 & $09^{\circ} 35^{\prime} \mathrm{S} / 77^{\circ} 19 \mathrm{~W}$ & 1977 & 2 \\
\hline Chacaltaya & Bolivia & 0.082 & $16^{\circ} 21^{\prime} S / 68^{\circ} 07^{\prime} \mathrm{W}$ & 1992 & 1 \\
\hline Zongo & Bolivia & 2.1 & $16^{\circ} 15^{\prime} \mathrm{S} / 68^{\circ} 10^{\prime} \mathrm{W}$ & 1992 & 1 \\
\hline Echaurren Norte & Chile & 0.4 & 33여'S / 70008'W & 1975 & 3 \\
\hline Piloto Este & Argentina & 0.504 & $32^{\circ} 27^{\prime} \mathrm{S} / 70^{\circ} 09^{\prime} \mathrm{W}$ & 1979 & 4 \\
\hline Los tres & Argentina & $\mathrm{s} / \mathrm{i}$ & $49^{\circ} 20^{\prime} \mathrm{S} / 73^{\circ} 00 \mathrm{~W}$ & 1996 & 1 \\
\hline
\end{tabular}

s/i: sin información

Fuentes:

1.- IAHS/UNESCO 1999
2.- Francou et al. 1995

3.- DGA 1995

4.- LEIVA and CABRERA 1996

TABLA 3

Balances de Masa (mm eq. de agua) en Bolivia y Chile central

\begin{tabular}{|l|c|c|c|c|c|c|c|c|c|}
\hline Glaciar & Balance & Balance & Balance & Balance & Balance & Balance & Balance & Balance & Fuente \\
& $91 / 92 @$ & $92 / 93$ & $93 / 94$ & $94 / 95$ & $95 / 96$ & $96 / 97$ & $97 / 98 @$ & $98 / 99 *$ & \\
\hline Zongo & $-1,380$ & +20 & -650 & $-1,250$ & -675 & +797 & $n / i$ & $n / 1$ & 1,2 y 3 \\
Echaurren Norte & $+1,740$ & -290 & $-1,860$ & -950 & $-1,180$ & $-2,890$ & $+2,890$ & $-4,070$ & 4 y 5 \\
\hline
\end{tabular}

@ Año hidrológico con evento El Niño

* Año hidrológico con evento La Niña

n/i: información no disponible

Fuentes:

1.- IAHS/UNESCO 1994

2.- IAHS/UNESCO 1996
3.- IAHS/UNESCO 1999

4.- DGA 1997

5.- Comunicación personal Carlos GARÍN para años 1997/1999

TABLA 4

Acumulación Anual de Nieve en el Glaciar Chico y Echaurren Norte

\begin{tabular}{|r|l|l|}
\hline \multirow{2}{*}{ Año hidrológico } & \multicolumn{2}{|c|}{ Acumulación en cm eq. de agua a-1 } \\
\cline { 2 - 3 } & Glaciar Chico (1) & Glaciar Echaurren Norte (2 y 3) \\
\hline $1996-97^{\star}$ & 120 & 43 \\
$1997-98 @$ & 36 & 445 \\
\hline
\end{tabular}

* Año hidrológico con evento La Niña

@ Año hidrológico con evento El Niño

Fuentes:

1.- CASASSA and RIVERA (submitted),

2.- DGA 1997,

3.- Comunicación personal Carlos GARíN (DGA) para años 1997-1998. 
interrumpidos por los años 1981/82 y 1983/ 84 (DGA 1995).

2.- Desde 1988/89 (un fuerte año La Niña) hasta 1998/99 (otro año La Niña), hubo una clara tendencia de balances negativos, sólo interrumpidos por los años El Niño 1991/92 y $1997 / 98$.

En el primer período, si bien hubo algunos años La Niña como 1984/85, el impacto de estos años no fue negativo, por lo que los balances de masa siguieron acumulándose positivamente en el glaciar Echaurren.

En el segundo período, se acentuaron las respuestas extremas del glaciar, por lo que la ocurrencia de tres eventos La Niña de gran magnitud (1988, 1996 y 1998), generó una tendencia claramente regresiva.

Estas respuestas extremas, pueden explicarse porque los efectos de eventos ENOS en glaciares de Chile central, están ligados principalmente a cambios en las precipitaciones y no tanto a cambios en el régimen térmico. Esta relación más estrecha con las precipitaciones también ha sido verificada en el único balance de masa publicado para los Andes de Argentina central (LEIVA and CABRERA 1996).

Interesante resulta constatar que la relación existente entre el fenómeno ENOS y los balances de masa en glaciares tropicales es bastante contrastada, dependiendo de su localización específica (Tabla 2).

En general, los glaciares tropicales son impactados negativamente por los fenómenos El Niño, debido principalmente al aumento de las temperaturas, que generan una fuerte ablación con un aumento considerable de la escorrentía (RIBSTEIN et al. 1995; FRANCOU and SICART 1999). Respecto de las precipitaciones, no existe en general una buena correlación con los fenómenos ENOS, no obstante generar menores precipitaciones o períodos de lluvia más cortos, los que a] coincidir con el período de máxima ablación (verano), refuerzan los balances de masa negativos (FRANCOU et al. 1995).

Al comparar un glaciar tropical (el glaciar Zongo) con el de Chile central (Echaurren), queda claro que ante la presencia de eventos ENOS, las respuestas de ambos glaciares son extremadamente opuestas. Sin embargo, en ausencia de eventos ENOS, ambos glaciares presentan balances de masa negativos, lo que implicaría un aumento del flujo de energía que están recibiendo (Tabla 3).

En Sudamérica, los balances de masa se han llevado a cabo en glaciares que poseen áreas pequeñas, (Tabla 2), los que si bien poseen varias ventajas logísticas, técnicas y económicas para su selección y monitoreo, no son los más representativos en términos de balances de masa acumulados, puesto que se ubican en un rango de fluctuación muy sensible a nivel interanual, sin tendencias claras de mediano o largo plazo (IAHS/UNESCO 1998). De acuerdo a HAEBERLI, (1998), es necesario medir glaciares más grandes y con mayor desarrollo altitudinal, que permitan estimar respuestas más definitivas frente a oscilaciones climáticas multianuales.

En el sur del país, CASASSA and RIVERA (submitted) generaron un modelo topográfico de balance de masa para el Campo de Hielo Sur, el cual debió asumir, debido a la falta de datos más precisos, una condición de equilibrio inexistente en la realidad. Este modelo fue contrastado con una estimación de balance de masa cuaternario de HULTON and SUGDEN (1995).

Las primeras mediciones de acumulación anual de nieve para un balance de masa en el CHS, se realizaron gracias a la instalación en Enero de 1996 de una torre de $10 \mathrm{~m}$ de altura en la zona de acumulación del glaciar Chico (Fig. 1), la que permitió detectar una alta variabilidad de la acumulación de nieve entre 1997 y 1998 , la cual podría deberse a fluctuaciones en las precipitaciones, tal como ha sido registrado en estaciones aledañas al CHS durante las últimas décadas (ROSENBLÜTH et al. 1995; IBARZABAL et al. 1996).

Sin embargo, vuelve a producirse un contraste latitudinal significativo con respecto a Chile central (Tabla 4), con comportamientos inversos desde el punto de vista nivológico, posiblemente relacionado con las alteraciones climáticas generadas por la presencia de eventos ENOS.

Entre las perspectivas futuras, se espera que en los próximos años se efectúen nuevas mediciones puntuales de balance de masa en el CHS, mediante torres de acumulación, magnetos enterrados en nieve y testigos de hielo. En 


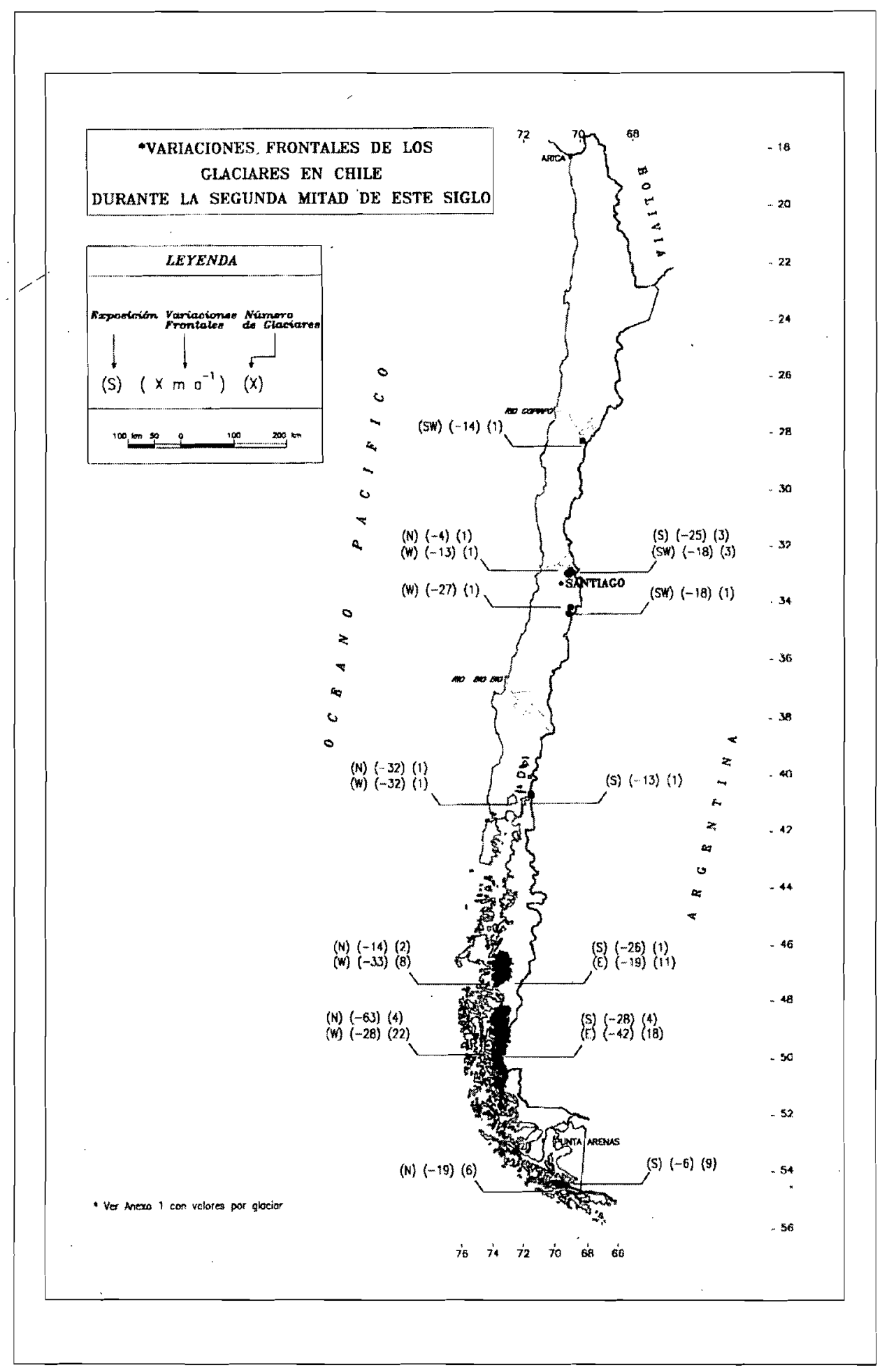

Fig.3. Variaciones frontales de glaciares en Chile.

Fig.3. Frontal glacier variations in Chile. 
Chile central, se espera realizar nuevos estudios de balance de masa, en glaciares más grandes, tales como el Juncal Norte (Fig. 1) en la cuenca del Aconcagua (Tabla 1).

Sin embargo, uno de los principales avances en los últimos años, ha sido el empleo de sensores satelitales activos del tipo radar, en áreas remotas, de difícil acceso y condiciones climáticas extremas. Las imágenes de radar han permitido realizar observaciones interferométricas y de correlación de fase, que tienen grandes aplicaciones en la confección de modelos digitales de terreno con topografía superficial, estimación de velocidades superficiales del hielo y determinación precisa de variaciones frontales del hielo.

En términos de balances de masa, hasta la fecha se ha empleado una combinación de datos interferométricos, datos de terreno y modelación del flujo del hielo, para estudiar el balance de los glaciares Perito Moreno (ROTT et al. 1998; MICHEL and RIGNOT 1999) y San Rafael (RIGNOT et al. 1996a y 1996b).

En adición a los objetivos mencionados, se han empleado imágenes de radar para estimar los efectos de las condiciones climáticas sobre la superficie glaciar (FORSTER 1997; FORSTER et al. 1996; FORSTER et al. 1997).

\section{Testigos de hielo}

Durante las últimas dos décadas, se han realizado algunas extracciones de testigos de hielo desde zonas de acumulación de glaciares en Chile. La mayoría de estos testigos tienen un largo de pocos metros, por lo que han servido principalmente para estimar tasas de acumulación de nieve, más que variaciones climáticas seculares.

En el CHN, YAMADA (1987) extrajo un testigo de $37.6 \mathrm{~m}$ desde la zona de acumulación del glaciar San Rafael (Fig. 1), lo que permitió estimar una tasa de acumulación de nieve de +3.45 m equivalentes de agua para el año 1984 . En este testigo se detectó un acuífero a una profundidad de ca. $27 \mathrm{~m}$, lo que evidencia la importancia de los procesos de fusión y percolación en Patagonia.

En el año 1996, MATSUOKA et al. (1998) extrajeron un testigo de hielo de $14.5 \mathrm{~m}$ de largo, desde la zona de acumulación del glaciar Nef en el CHN (Fig. 1), el que junto a otras mediciones climáticas y glaciológicas, permitieron estimar un balance de masa neto para el año calendario $1996 \mathrm{de}+2.2 \mathrm{~m}$ equivalentes de agua (MATSUOKA and NARUSE 1999).

En el CHS, ARISTARAIN and DELMAS (1993) extrajeron un testigo de $13.2 \mathrm{~m}$ de largo, desde la zona de acumulación del glaciar Perito Moreno (Fig. 1), a una altura aproximada de 2,680 msnm en 1986. Considerando las acumulaciones de los veranos 1980/81 a 1985/ 86 , calcularon una tasa de acumulación anual $\mathrm{de}+1.2 \mathrm{~m}$ equivalentes de agua, lo que ha sido considerado como un dato puntual muy bajo $y$ poco representativo de las acumulaciones normales en el CHS (CASASSA and RIVERA submitted; MATSUOKA and NARUSE 1999).

En el Norte Chico, un equipo de investigadores suizos extrajo un testigo de hielo de $36 \mathrm{~m}$ de largo, desde la zona de acumulación del glaciar del Cerro Tapado (Fig. 1). Según los primeros análisis químicos e isotópicos de este testigo, se ha estimado que este glaciar sólo presentaría acumulaciones significativas en años con presencia de eventos El Niño (SCHWIKOWSKI et al. 1999).

En noviembre de 1999, un equipo de glaciólogos japoneses en conjunto con el Laboratorio de Glaciología de la Universidad de Chile y la Universidad de Magallanes, extrajeron un

\section{TABLA 5}

Variaciones Históricas Glaciar Cipreses (34³3'S/70²2’W)

\begin{tabular}{|r|c|l|}
\hline Periodo & Tasas de retroceso anual $\left(\mathrm{m} \mathrm{a}^{-}{ }^{-}\right)$ & Fuente \\
\hline $1860-1888$ & 10 & CAVIEDES 1979 \\
$1888-1955$ & 11 & Este trabajo \\
$1955-1968$ & 27 & Este trabajo \\
$1968-1997$ & 30 & Este trabajo \\
\hline
\end{tabular}


testigo de hielo de mediana profundidad (46 m) desde la zona de acumulación del glaciar Tyndall (Fig. 1) del CHS, lo que se espera aporte antecedentes climáticos y de balance de masa para esta parte del país.

\section{Variaciones frontales y areales (anexo 1)}

\section{Norte Grande (18 $\left.{ }^{\circ} \mathrm{S}-27^{\circ} \mathrm{S}\right)$}

Si bien en esta zona la cordillera andina presenta una gran altura sobre el nivel del mar, hay muy pocos volcanes y centros montañosos con glaciaretes y cubiertas de nieve semipermanente, muchos de los cuales fueron inventariados como glaciares por GARÍN (1987). Entre los posibles glaciares de la zona, destaca uno en las laderas occidentales del Volcán Llullaillaco (Fig. 1), que ha sido definido sólo como un campo de nieve semipermanente por GROSJEAN et al. (1991), MESSERLI et al. (1993) y MESSERLI et al. (1998). De acuerdo a JENNY and KAMMER (1996) desde el volcán Parinacota $\left(18^{\circ} 08^{\prime} \mathrm{S} / 69^{\circ} 08^{\prime} \mathrm{W}\right)$ hasta el Nevado de Tres Cruces $\left(27^{\circ} 05^{\prime} \mathrm{S} / 68^{\circ} 47^{\prime} \mathrm{W}\right)$ no habrían glaciares (Fig. 1).

Según LLIBOUTRY et al. (1958), los pocos glaciares de esta zona no presentaban evidencias de retroceso sensible entre las décadas del $30 \mathrm{y}$
50.

\section{Norte Chico $\left(27^{\circ} \mathrm{S}-32^{\circ} \mathrm{S}\right)$}

En el Norte Chico sólo se ha medido el glaciar Tronquitos $\left(28^{\circ} 32^{\prime} \mathrm{S} / 69^{\circ} 43^{\prime} \mathrm{W}\right)$, ubicado en la cuenca superior del río Copiapó (Fig. 1), que posee gran altura (sobre $4750 \mathrm{msnm}$ ) y temperaturas muy bajas, lo que genera hielo de bajas temperaturas (frío), con escasa dinámica y movimiento. Su tasa de retroceso frontal es de $14 \mathrm{~m}$ a-1 en el período 1955-1984, con una escasa pérdida de superficie (RIVERA y ACUÑA, 1997).

En 1985, el glaciar Estero Seco de los Tronquitos $\left(28^{\circ} 33^{\prime} \mathrm{S} / 69^{\circ} 43^{\prime} \mathrm{W}, 1.72 \mathrm{~km} 2 \mathrm{de}\right.$ superficie), ubicado a $2.5 \mathrm{~km}$ al sureste del glaciar Tronquitos (Fig. 1), generó un gran aluvión que descendió hasta el embalse Lautaro, producto de la ruptura de una represa glacial, fenómeno conocido como "Jökulhlaup" (PEÑA y ESCOBAR 1987).

\section{Chile Central $\left(32^{\circ} \mathrm{S}-35^{\circ} \mathrm{S}\right)$}

En Chile central (regiones V a VI) se han evaluado 8 glaciares, los que muestran una clara tendencia de retroceso con tasas bajas pero variables, dependiendo de sus condiciones locales (Fig. 3).

\section{TABLA 6}

\section{Variaciones Históricas Glaciar San Rafael (46² $41^{\prime} S / 73^{\circ} 51^{\prime} W$ )}

\begin{tabular}{|r|c|l|}
\hline Periodo & Tasas de variación anual $(\mathbf{m}$ a- $)$ & Fuente \\
\hline $1871-1905$ & -30 & BRÜGGEN 1950 (241) \\
\hline $1905-1935$ & -230 & BRÜGGEN 1950 (242) \\
\hline $1935-1945$ & $+200^{*}$ & LLIBOUTRY 1956 (383) \\
\hline $1945-1958$ & Estable con leve avance & LAWRENCE and LAWRENCE in WARREN 1993 \\
\hline 1958 & Avance contra bosques & HEUSSER, 1960 (563) \\
\hline 1964 & Se mantiene presión del hielo contra el bosque & SHIPTON in WARREN 1993 \\
\hline $1945-1974$ & -20 & ANIYA and ENOMOTO 1986 \\
\hline $1974-1984$ & -200 & ANIYA and ENOMOTO 1986 \\
\hline $1984-1986$ & -100 & KONDO and YAMADA 1988 \\
\hline $1984-1991$ & -215 & WARREN 1993 \\
\hline $1991-1992$ & +50 & WARREN 1993 \\
\hline $1992-1993$ & Estable & WARREN 1993 \\
\hline $1993-1999$ & Estable con leve retroceso & Este trabajo \\
\hline
\end{tabular}

*Este dato fue discutido por WINCHESTER and HARRISON (1996) como un error en la estimación de BRÜGGEN. Aseguran que entre 1935 y 1945 hubo sólo fluctuaciones menores 


\section{TABLA 7}

Variaciones Históricas Glaciar Pío XI (49²12'S/74º3'W)

\begin{tabular}{|c|c|c|c|}
\hline \multicolumn{2}{|c|}{ (Periodo) Tasas de variación anual en $\mathrm{m}$ a- ${ }^{1}$} & \multicolumn{2}{|c|}{ Fuente } \\
\hline \multicolumn{2}{|c|}{$(1830-1925) 126$} & \multicolumn{2}{|c|}{ Este trabajo } \\
\hline \multicolumn{2}{|c|}{$(1925-1926) 1000$} & \multicolumn{2}{|c|}{ AGOSTINI 1945} \\
\hline \multicolumn{2}{|c|}{ (1926 - 1928) Estable con leve avance } & \multicolumn{2}{|c|}{ RIVERA 1992} \\
\hline \multicolumn{2}{|c|}{$(1928-1945)-147$} & \multicolumn{2}{|c|}{ RIVERA et al. 1997 a } \\
\hline Frente sur & Frente norte & Fuente Frente sur & Fuente Frente norte \\
\hline$(1945-1951) 750$ & \multirow[t]{3}{*}{$(1945-1975) 130$} & RIVERA et al. 1997 a & \multirow[t]{3}{*}{ WARREN et al. 1997} \\
\hline$(1951-1969) 142$ & & RIVERA et al. $1997 \mathrm{a}$ & \\
\hline$(1969-1976) 345$ & & RIVERA et al. $1997 \mathrm{a}$ & \\
\hline$(1976-1981) 120$ & $(1975-1981) 83$ & RIVERA et al. 1997 a & WARREN et al. 1997 \\
\hline$(1981-1985)-300$ & $(1981-1984) 100$ & RIVERA et al. 1997 a & WARREN et al. 1997 \\
\hline$(1985-1992) 180$ & \multirow[t]{2}{*}{$(1984-1993) 89$} & RIVERA et al. 1997 a & \multirow[t]{2}{*}{ WARREN et al. 1997} \\
\hline$(1992-1993) 400$ & & RIVERA et al. $1997 \mathrm{a}$ & \\
\hline$(1993-1994) 1,000$ & $(1993-1994) 800$ & RIVERA et al. 1997 a & WARREN et al. 1997 \\
\hline$(1994-1995)-800$ & \multirow{2}{*}{$\begin{array}{c}(1994-2000) \\
\text { Estable con leve retroceso }\end{array}$} & RIVERA et al. $1997 \mathrm{~b}$ & \multirow[t]{2}{*}{ Este trabajo } \\
\hline $\begin{array}{c}(1995-2000) \text { Estable } \\
\text { con leve retroceso }\end{array}$ & & Este trabajo & \\
\hline
\end{tabular}

El mayor retroceso lo ha experimentado el glaciar Juncal Sur (Fig. 1) con cerca de $50 \mathrm{~m}$ a1 desde 1955 a 1997. Descendiendo del mismo cordón cordillerano, pero en dirección norte, se ubica el glaciar Juncal Norte (Fig. 1), que presenta las menores tasas de retroceso de Chile central para el período $1955-1997$, con $-4 \mathrm{~m}$ a1 . En este último caso, la abrupta topografía que rodea la lengua terminal, genera un fuerte estrechamiento de horizonte, que impide la insolación potencial del hielo, reduciendo la efectividad de la ablación.

Destaca en esta zona central del país el glaciar Cipreses, ubicado en la cuenca del Cachapoal (Fig. 1), el cual fue visitado por primera vez en 1860 (CAVIEDES 1979). Como puede apreciarse en la Tabla 5 , este glaciar ha experimentado un permanente proceso de retroceso, el cual se ha acentuado en las últimas décadas, donde las tasas de retroceso se han triplicado.

Entre la región VII y $\mathrm{X}$ del país, se han estudiado las variaciones recientes de los glaciares del Monte Tronador, el cual posee una gran superficie de hielo que fluye tanto hacia Argentina, donde se ubica el glaciar Frías (Fig. 1) que ha sido documentado detalladamente por
VILLALBA et al. (1990), como hacia Chile, donde se ubican varias lenguas recubiertas o glaciares regenerados a los pies de imponentes cascadas de hielo (RIVERA 1989).

Entre las lenguas que fluyen hacia Chile destaca el glaciar Casa Pangue y Blanco Chico (Fig. 1), con tasas de retroceso de $32 \mathrm{~m}$ a-1 en el período 1961-1995. Este último, presentaba una posición frontal muy estable sobre una morrena de empuje visible en 1955 con un frente desprendente en un lago proglacial. Sin embargo, en la medida que se despegó de dicho soporte o pinning point, el retroceso se aceleró por el aumento del desprendimiento de témpanos (calving), formándose un lago de más de $2 \mathrm{~km}$ de largo en el sector desocupado por el retroceso del glaciar (RIVERA y ACUÑA 1997).

\section{Región Austral}

En la región de Aysén, además del CHN y CHS, no se han medido variaciones recientes de glaciares. Sin embargo, durante la última erupción del volcán Hudson (Fig. 1) pudo constatarse que uno de sus glaciares, el del río Bayo (en el margen oriental de la caldera volcánica), había retrocedido cerca de $1.8 \mathrm{~km}$ (NARANJO et al. 1993), lo que determina una 
tasa de retroceso de aproximadamente $38 \mathrm{~m}$ a1 para el período 1944/45-1991.

\section{Campo de Hielo Norte (CHN)}

En los Campos de Hielo Patagónicos Norte y Sur (Fig. 1), se ha concentrado gran parte de las últimas investigaciones glaciológicas, gracias a numerosos proyectos internacionales, entre los que destacan equipos japoneses y británicos (WARREN and SUGDEN, 1993).

En el Campo de Hielo Norte (CHN), ANIYA (1988), generó el primer inventario de glaciares de la zona, el cual se basó en los pioneros trabajos de LLIBOUTRY (1956), fotografías aéreas recientes y varias campañas de terreno. En términos generales, los glaciares del $\mathrm{CHN}$ experimentaron un fuerte retroceso desde 1944/
45, sin embargo en los inicios de la década de los noventa esta tendencia se habría aminorado.

Destacan las variaciones experimentadas por el glaciar San Rafael (Tabla 6), que desde un máximo a mediados del siglo pasado, tuvo un fuerte retroceso hasta la década del 30 , cuando comenzó a avanzar, proceso que alcanzó hasta mediados de los 60, a partir de lo cual comenzó un rápido retroceso que alcanzó las máximas tasas en la década de los 80 , debido a que su frente se ubicó en una zona de gran profundidad de la laguna homónima, lo que habría aumentado la efectividad del calving (WARREN 1993; WARREN et al. 1995).

En la década de los noventa, las fuertes tasas de retroceso del CHN se redujeron, especialmente en el lado oriental, donde incluso

\section{TABLA 8}

\section{Velocidades de Glaciares en Chile}

\begin{tabular}{|c|c|c|c|c|}
\hline $\begin{array}{l}\text { NOMBRE } \\
\text { GLACIAR }\end{array}$ & $\begin{array}{c}\text { VELOCIDADES } \\
\mathrm{m} \mathrm{d} \mathbf{- 1}^{-1} \\
\end{array}$ & $\begin{array}{c}\text { PERIODO } \\
\text { DE MEDICION }\end{array}$ & $\begin{array}{c}\text { METODO } \\
\text { DE MEDICION }\end{array}$ & FUENTE \\
\hline \multirow[t]{2}{*}{ San Rafael } & 17 a 22 & Octubre, 1985 a Enero 1986 & Taquimetría & $\begin{array}{l}\text { KONDO and } \\
\text { YAMADA } 1988\end{array}$ \\
\hline & 2.5 a 17.5 & $8-10$ Octubre, 1994 & Interferometría & RIGNOT et al. $1996 \mathrm{~b}$ \\
\hline \multirow[t]{2}{*}{ Soler } & 0.47 a 0.82 & $1983-1985$ & $\begin{array}{c}\text { Separación de ojivas en } \\
\text { fotos aéreas }\end{array}$ & $\begin{array}{c}\text { ANIYA and } \\
\text { NARUSE } 1987\end{array}$ \\
\hline & 1.5 & Octubre a Noviembre, 1985 & Taquimetría & NARUSE 1987 \\
\hline San Quintin & 2.1 & Octubre, 1994 & Interferometría & RIGNOT et al. 1996 a \\
\hline Gualas & 0.99 & Octubre, 1994 & Interferometría & RIGNOT et al. 1996 a \\
\hline Reicher & 2.5 & Octubre, 1994 & Interferometría & RIGNOT et al. 1996 a \\
\hline \multirow[t]{2}{*}{ Upsala } & 4.44 & 21-29 Noviembre, 1993 & Taquimetría & SKVARCA et al. 1995 \\
\hline & 3.7 & $14-18$ Noviembre, 1990 & Taquimetría & NARUSE et al. $1992 \mathrm{a}$ \\
\hline \multirow[t]{4}{*}{$\begin{array}{l}\text { Perito } \\
\text { Moreno } \\
\end{array}$} & $1.1 \mathrm{a} 2.19$ & $9-10$ Octubre, 1994 & Interterometría & $\begin{array}{l}\text { MICHEL and } \\
\text { RIGNOT } 1999\end{array}$ \\
\hline & 2.1 a 5 & $14-18$ Noviembre, 1990 & Taquimetria & NARUSE et al. 1992 a \\
\hline & 0.5 a 3.5 & Octubre, 1994 & Interterometría & ROTT et al. 1998 \\
\hline & 2.64 & $\begin{array}{c}\text { Noviembre, } 1993 \text { a } \\
\text { Diciembre, } 1994\end{array}$ & Taquimetría & $\begin{array}{l}\text { SKVARCA and } \\
\text { NARUSE } 1997\end{array}$ \\
\hline \multirow[t]{3}{*}{ Tyndall } & 0.1 a 1.9 & $\begin{array}{l}30 \text { de Noviembre } 1985 \\
\text { a } 3 \text { de Diciembre } 1985\end{array}$ & Taquimetría & NARUSE et al. 1987 \\
\hline & 0.07 a 0.51 & 7-15 Diciembre, 1990 & Taquimetría & KADOTA et al. 1992 \\
\hline & 0.065 a 0.61 & 9-18 Diciembre, 1993 & Taquimetría & NISHIDA et al. 1995 \\
\hline Penguin & 0.9 a 2.2 & Octubre, 1994 & Interferometría & FORSTER et al. 1999 \\
\hline Pío XI & 1 a 50 & $14-17$ Noviembre, 1995 & Taquimetría & RIVERA et. al. 1999 \\
\hline Arenales & 0.39 a 0.49 & $1975-1979$ & $\begin{array}{l}\text { Separación de ojivas } \\
\text { en fotos aéreas }\end{array}$ & $\begin{array}{l}\text { WINCHESTER and } \\
\text { HARRISON } 1997\end{array}$ \\
\hline
\end{tabular}


dos glaciares experimentaron leves avances, 10 cual fue analizado como una respuesta a un ciclo con anomalías pluviométricas positivas en la década de los 70 (ANIYA and WAKAO 1997). En el lado occidental del CHN el comportamiento de los glaciares sería similar, puesto que el glaciar San Rafael ha estado estable desde 1991 hasta marzo de 1999 , cuando fueron tomadas fotografías desde aviones comerciales (Tabla 6).

No obstante lo anterior, el glaciar San Quintín ubicado inmediatamente al sur del glaciar San Rafael (Fig. 1), experimentó una disminución en su tasa de retroceso a fines de los ochenta y principios de los noventa, con un pequeño avance entre 1991 y 1993 (WINCHESTER and HARRISON 1996). Luego este glaciar comenzó una acelerada pérdida de masa en 1994 causado por el retroceso de su lengua sur en un lago proglacial. En fotografías tomadas desde aviones comerciales en marzo de 1999, el glaciar retrocedió aproximadamente $1.5 \mathrm{~km}$ comparado con la posición de 1993, debido a que todo el frente del glaciar está rodeado por un lago proglacial, con signos de colapso generalizado, con un gran número de témpanos, grietas radiales saturadas de agua y un gran lago en una de las lenguas marginales del lado sur.

En este contexto, se espera que el glaciar San Quintín continúe retrocediendo fuertemente, hasta alcanzar una posición de equilibrio, en el quiebre de pendiente que se advierte a $7 \mathrm{~km}$ aguas arriba, a los pies de la falla Liquiñe Ofqui (MURDIE et al. 1993), la que también podría estar controlando la profundidad y efectividad del desprendimiento de témpanos en el vecino glaciar San Rafael (WARREN 1993; WARREN et al. 1995).

Otros glaciares del CHN, tales como el Reicher, Gualas, Nef y Steffen (Fig. 1) (WADA and ANIYA 1995; ANIYA et al. 1997), han experimentado la desintegración de sus lenguas en lagos proglaciales, debido al drástico incremento de la tasa de desprendimiento de témpanos que se genera en frentes que flotan o aumentan sus velocidades (VAN DER VEEN 1996). Esta condición se agudiza al disminuir el espesor de hielo, sometido a fuerte ablación y adelgazamiento, por las tendencias de calentamiento global que afectan esta área (ROSENBLÜTH et al. 1997).

El volumen total de hielo perdido por retroceso en el CHN, para el período de 51 años a partir de 1944/45, es de 6.4 a $19.2 \mathrm{~km} 3$ (ANIYA and WAKAO, 1997).

\section{Campo de Hielo Sur (CHS)}

En el CHS, se realizó el primer levantamiento aerofotogramétrico en 1944/45 con el vuelo Trimetrogon. Con dichas fotos, la Fuerza Aérea de los EEUU y el Instituto Geográfico Militar (IGM), generaron una cartografía preliminar escala 1:250.000, que permitió determinar una superficie total aproximada de $13.500 \mathrm{~km} 2 \mathrm{de}$ hielo (LLIBOUTRY 1956). Con un mosaico de imágenes Landsat TM de 1986, ANIYA et al. (1996) estimó que el CHS tenía una superficie de $13,000 \mathrm{~km} 2$ en 1986 , lo que representa una pérdida de masa de aproximadamente un $4 \%$ para el período de 41 años desde 1944/45.

De los 48 principales glaciares del CHS descritos por ANIYA et al. (1997), la mayoría muestra retrocesos de sus frentes terminales durante este siglo, destacándose el fuerte retroceso que ha experimentado el glaciar O'Higgins (Fig. 1) con $14.6 \mathrm{~km}$. entre 1896 y 1995 (CASASSA et al. 1997).

Un pequeño grupo de glaciares, entre los que destacan los glaciares Oriental y Calvo, han presentado cierta estabilidad de sus frentes terminales, no evidenciando grandes diferencias en las últimas décadas.

Sólo dos glaciares han presentado avances, el Perito Moreno (ANIYA and SKVARCA, 1992) y principalmente el Pío XI (Tabla 7).

En 1830, el HMS Beagle visitó Patagonia Occidental, dibujando la línea de costa del fiordo Eyre, cerca de $20 \mathrm{~km}$ hacia el noreste del actual frente del glaciar (IWATA 1983). Esta línea de costa, donde se ubica el glaciar Pío XI, fue reproducida en varias cartas chilenas (RISOPATRON 1905), hasta que AGOSTINI (1945) visitó la zona y describió la historia de un colono noruego que intentó fundar una estancia en la cabecera del fiordo Eyre el año 1925 , pero que debió abandonar la zona ante el fuerte avance del glaciar. Se ha estimado que entre 1830 y 1925 el glaciar avanzó ca. 10.5 $\mathrm{km}$.

Después del avance de 1925-1928, este glaciar ha tenido otros dos períodos con fuertes avances, 


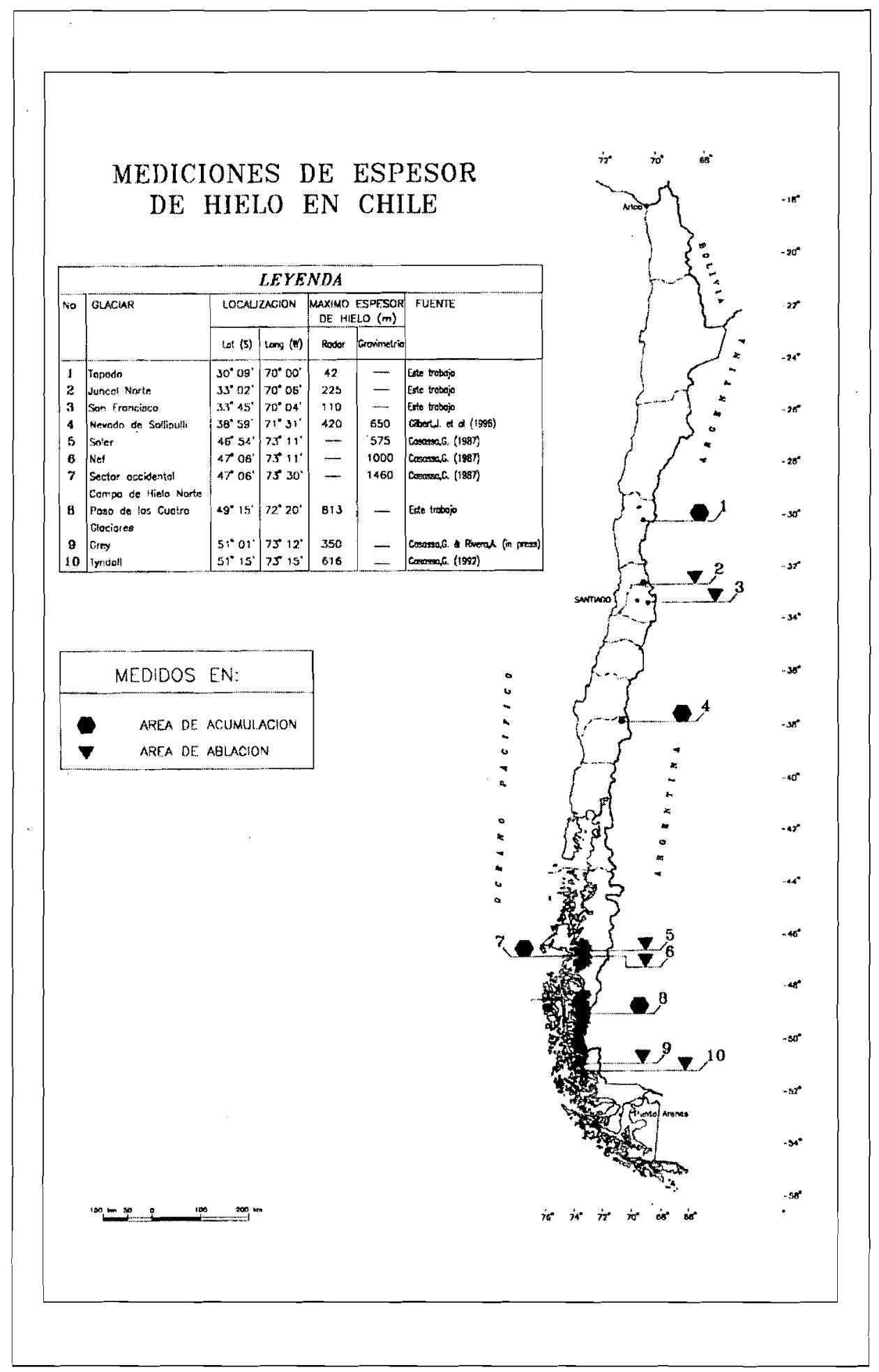

Fig. 4. Mediciones de espesor de hielo en Chile.

Fig. 4. Ice thickness measurements in Chile. 
1945-1951 y 1992-1994 (RIVERA et al. 1997 a y 1997b). A partir de este último ciclo de avance, el glaciar ha tendido a retroceder lentamente hasta Marzo del año 2000, fecha de la última visita de los autores.

El avance del frente norte del glaciar, embalsó a partir de 1951 el valle del río Greve, formando un lago de aproximadamente $240 \mathrm{~km} 2$ y $150 \mathrm{~m}$ sobre el nivel del mar. Este frente ha avanzado casi ininterrumpidamente hasta 1994 (WARREN et al. 1997). Desde dicha fecha hasta Marzo del 2000, el frente está estable con un leve retroceso.

Entre las causas que explican este anómalo comportamiento, se han discutido diversas hipótesis hipsométricas, volcánicas y glaciodinámicas (WARREN and RIVERA, 1994; RIVERA et al. 1997a y 1997b).

En términos de cambios en las superficies de glaciares del CHS, las variaciones entre 1944 y 1986 presentan las siguientes características:

Las tasas de pérdida de superficie promedio varían con gran amplitud, desde 0 $\mathrm{km} 2$ a-1 hasta $1.21 \mathrm{~km} 2$ a-1. Destaca por lo elevado de sus valores, la pérdida de área del glaciar O'Higgins, que entre 1986 y 1995 alcanzó 1.7 km2 a-1 (CASASSA et al. 1997). Aquellos glaciares localizados en la mitad norte del CHS (al norte de $50^{\circ} \mathrm{S}$ ) tienen mayores retrocesos que los ubicados en la mitad sur.

- Los glaciares localizados en el margen oriental del CHS tienen mayor retroceso que los ubicados en el margen occidental.

- El volumen de hielo perdido en 41 años, desde 1944/45 a 1986 debido al retroceso de las lenguas se ha estimado entre 40 y $80 \mathrm{~km} 3$ (ANIYA 1999).

\section{Cordillera Darwin (Fig. 1)}

En la Cordillera Darwin, HOLMLUND and FUENZALIDA (1995) analizaron las variaciones recientes de 16 glaciares, detectando las respuestas asimétricas que existen entre los glaciares de exposición norte y este, que han retrocedido con algunas escasas excepciones, mientras que en las laderas sur,

TABLA 9

Cambios de Espesor en Glaciares del Campo de Hielo Sur

\begin{tabular}{|c|c|c|c|}
\hline $\begin{array}{c}\text { NOMBRE DEL } \\
\text { GLACIAR }\end{array}$ & $\begin{array}{c}\text { TASAS }\left(\mathrm{m} \mathrm{a}^{-1}\right) \text { de } \\
\text { ADELGAZAMIENTO (-) } \\
\text { ENGROSAMIENTO (+) }\end{array}$ & $\begin{array}{l}\text { PERIODO DE } \\
\text { MEDICION }\end{array}$ & FUENTE \\
\hline \multirow[t]{3}{*}{ O'Higgins } & -3.2 & $1914-1933$ & CASASSA et al. 1997 \\
\hline & -6.7 & $1933-1960$ & CASASSA et al. 1997 \\
\hline & $-2.5 a-11$ & $1975-1995$ & CASASSA et al. 1997 \\
\hline Pío XI & +2.2 & $1975-1995$ & RIVERA and CASASSA 1999 \\
\hline \multirow[t]{2}{*}{ Upsala } & -3.6 & $1968-1990$ & ANIYA et al. 1997 \\
\hline & $-9.5 a-14$ & $1991-1993$ & NARUSE et al. 1995 \\
\hline Ameghino & -2.3 & $1949-1993$ & ANIYA 1999 \\
\hline Perito Moreno & sin cambios & $1991-1993$ & SKVARCA and NARUSE 1997 \\
\hline Dickson & $-2.5 a-8.1$ & $1975-1998$ & Este trabajo \\
\hline Grey & -2.3 & $1975-1995$ & CASASSA and RIVERA (inédito) \\
\hline \multirow[t]{4}{*}{ Tyndall } & -2.0 & $1945-1993$ & ANIYA et al. 1997 \\
\hline & -1.7 & $1975-1985$ & KADOTA et al. 1992 \\
\hline & -4.0 & $1985-1990$ & KADOTA et al. 1992 \\
\hline & -3.1 & $1990-1993$ & NISHIDA et al. 1995 \\
\hline Soler & -5.2 & $1983-1985$ & NARUSE 1987 \\
\hline San Quintin & -2.3 & $1907-1980$ & WINCHESTER and HARRISON 1996 \\
\hline Colonia & $-1.7 a-2.7$ & $1945-1975$ & ANIYA 1988 \\
\hline San Rafael & -1.0 & $1945-1975$ & ANIYA 1988 \\
\hline
\end{tabular}


TABLA 10

Ubicación de ESTACIONES METEOROLÓGICAS (FIG. 1).

\begin{tabular}{|l|c|c|}
\hline Nombre estación & $\begin{array}{c}\text { Ubicación en coordenadas } \\
\text { geográficas }\end{array}$ & Altura (m) \\
\hline Antóagasta & $23^{\circ} 26^{\prime} S / 70^{\circ} 26^{\prime} \mathrm{W}$ & 135 \\
La Serena & $29^{\circ} 54^{\prime} \mathrm{S} / 71^{\circ} 12^{\prime} \mathrm{W}$ & 142 \\
Punta Angeles & $33^{\circ} 01^{\prime} \mathrm{S} / 71^{\circ} 38^{\prime} \mathrm{W}$ & 41 \\
Quinta Normal & $33^{\circ} 27^{\prime} \mathrm{S} / 70^{\circ} 41^{\prime} \mathrm{W}$ & 520 \\
Temuco & $38^{\circ} 45^{\prime} \mathrm{S} / 2^{\circ} 38^{\prime} \mathrm{W}$ & 114 \\
Puerto Montt & $41^{\circ} 25^{\prime} \mathrm{S} / 73^{\circ} 05^{\prime} \mathrm{W}$ & 85 \\
Ancud & $41^{\circ} 54^{\prime} \mathrm{S} / 73^{\circ} 49^{\prime} \mathrm{W}$ & 20 \\
Isla Guafo & $43^{\circ} 12^{\prime} \mathrm{S} / 72^{\circ} 12^{\prime} \mathrm{W}$ & 140 \\
Puerto Aysén & $45^{\circ} 12^{\prime} \mathrm{S} / 72^{\circ} 24^{\prime} \mathrm{W}$ & 11 \\
Cabo Raper & $46^{\circ} 30^{\prime} \mathrm{S} / 75^{\circ} 24^{\prime} \mathrm{W}$ & 40 \\
Isla San Pedro & $47^{\circ} 24^{\prime} \mathrm{S} / 74^{\circ} 36^{\prime} \mathrm{W}$ & 22 \\
Lago Argentino & $50^{\circ} 20^{\prime} \mathrm{S} / 72^{\circ} 18^{\prime} \mathrm{W}$ & 220 \\
Bahía Félix & $52^{\circ} 58^{\prime} \mathrm{S} / 74^{\circ} 0^{\prime} \mathrm{W}$ & 15 \\
Evangelistas & $52^{\circ} 24^{\prime} \mathrm{S} / 75^{\circ} \mathrm{O} 6^{\prime} \mathrm{W}$ & 49 \\
Punta Arenas & $53^{\circ} \mathrm{B}^{\prime} \mathrm{S} / 70^{\circ} 54^{\prime} \mathrm{W}$ & 6 \\
\hline
\end{tabular}

los glaciares están cerca de sus posiciones máximas holocénicas.

\section{Velocidades}

La mayor parte de las mediciones de velocidad han sido realizadas en las zonas de ablación de glaciares patagónicos, donde los valores difieren dentro de cada glaciar y entre glaciares con frentes desprendentes y aquellos que tienen frentes de montaña (Tabla 8).

Las velocidades máximas detectadas, han sido medidas en glaciares con frentes desprendentes en fiordos o lagunas occidentales. El valor más alto se detectó en el glaciar Pío XI (Fig. 1), en cuyo frente sur se midieron velocidades de pocos metros cerca del margen, hasta un máximo de ca. $50 \mathrm{~m} \mathrm{~d}-1$, en un serac central. En promedio, la lengua terminal de éste glaciar tiene una velocidad aproximada de $20 \mathrm{~m} \mathrm{~d}-1$ (RIVERA et al. 1997b), lo que sería propio de un surging glacier (RIVERA et al. 1997a).

Los surging glaciers se caracterizan por presentar movimientos de avance muy bruscos y repentinos, con velocidades muy elevadas y superiores a las normales, lo cual se generaría por un traspaso rápido de masa desde la zona de acumulación a la de ablación (PATERSON 1994). En Sudamérica sólo se ha documentado este tipo de glaciares en los Andes centrales, donde el glaciar del Plomo (Cuenca del río Mendoza en Argentina), avanzo $2.7 \mathrm{~km}$ en aproximadamente 9 meses en 1985 (LLORENS and LEIVA 1995), el glaciar Juncal Sur, (Cuenca del Maipo) que en 1947 avanzó cerca de $3 \mathrm{~km}$ superando el Salto del Olivares, al igual que los repentinos avances de los glaciares del Nevado del Plomo (Fig. 1) en 1930 y del Río Museo en 1935 ambos en los Andes de Santiago, Cuenca del Maipo (LLIBOUTRY 1956).

Otro glaciar con velocidades muy altas es el San Rafael, que ha sido medido con técnicas taquimétricas tradicionales, alcanzando valores que oscilan entre 17 y $22 \mathrm{~m} \mathrm{~d}-1$, (NARUSE 1985; KONDO and YAMADA, 1988), consideradas como unas de las más altas para glaciares desprendentes del planeta. Empleando técnicas interferométricas, RIGNOT et al. (1996b), confirmaron las velocidades de seracs, medidas en el glaciar San Rafael por NARUSE (1985) y KONDO and YAMADA (1988).

En otros glaciares del $\mathrm{CHN}$ ubicados en el margen oriental, se han estimado velocidades menores a las de sus vecinos occidentales, destacando las mediciones en el glaciar Soler, con valores desde $0.27 \mathrm{~m} \mathrm{~d}-1$ (ANIYA and NARUSE 1987) hasta $1.2 \mathrm{~m} \mathrm{~d}-1$ NARUSE 
(1987). Otro glaciar con bajas velocidades es el Arenales, que fue medido por WINCHESTER and HARRISON (1997), alcanzando 0.39 a $0.49 \mathrm{~m} \mathrm{~d}-1$.

El glaciar Tyndall, ubicado en el margen oriental del CHS, ha sido medido en varias ocasiones desde mediados de $\operatorname{los} 80$, mostrando valores bajos, que han tendido a aumentar en las últimas mediciones (NISHIDA et al. 1995).

En términos temporales las velocidades son muy variables, dependiendo de la cantidad de agua subglacial, que a su vez depende de la temperatura y de la dinámica de flujo. A nivel horario las velocidades responden en forma directa al aumento de las temperaturas, por lo que son máximas en las tardes y mínimas temprano en las mañanas (NARUSE et al. 1992b; RIVERA et al. 1997b). A nivel intermensual, las velocidades son máximas en primavera y verano, por la mayor presencia de agua en la base del glaciar (PATERSON 1994; SKVARCA and NARUSE, 1997).

Para Chile central y norte, sólo existen estimaciones de velocidad pero no mediciones reales.

\section{Espesor de hielo y adelgazamientos}

\section{Espesor (Fig. 4)}

Las primeras mediciones de espesor de hielo realizadas en Chile, fueron hechas con el método gravimétrico en el Campo de Hielo Norte (CASASSA 1987), donde se estimó un espesor máximo de $1460 \mathrm{~m}$, definiendo una topografía subglacial por debajo del nivel del mar.

En el año 1990, en el contexto de campañas glaciológicas japonesas en Patagonia (NARUSE and ANIYA 1992), se midieron espesores de hielo en la zona de ablación del glaciar Tyndall (CASASSA 1992), las cuales permitieron detectar más de $600 \mathrm{~m}$ de espesor. Estas fueron hechas con un sistema de radio ecosondaje (radar) de captura análoga.

En el año 1992, un equipo de geólogos y vulcanólogos de la Universidad de Bristol, en conjunto con el Servicio Nacional de Geologia y Minería y la Universidad de Chile, realizaron mediciones de espesor de hielo, en el glaciar de la caldera del Nevado de Sollipulli (Fig. 1), determinándose espesores máximos de más de
$600 \mathrm{~m}$, al combinar datos de radar con gravimetría (GILBERT, et al. 1996). Con el método de radar, sólo se alcanzó un espesor máximo de $420 \mathrm{~m}$.

En 1993, se volvió a medir con un sistema digital de radar con traspaso a PC el glaciar Tyndall, detectándose valores de espesor levemente inferiores a los de 1990, debido presumiblemente al adelgazamiento ocurrido en e] período de dos años (CASASSA and RIVERA, 1998).

Con un sistema de radar de impulso montado en trineos y tirado por motos de nieve, se ha medido hasta $1300 \mathrm{~m}$ de espesor de hielo frío en Patriot Hills, Antártica, durante las campañas de 1996 y 1997 (RIVERA et al. 1998; CASASSA et al. 1998b). También se ha probado con éxito el método, en el hielo temperado del glaciar Chico del CHS, donde se midió poco más de $700 \mathrm{~m}$ durante la operación Hielo Azul de la FACH en 1997. En ambos casos, existen espesores totales de hielo bastante mayores, por lo que se requiere combinar sistemas de medición (gravimetríaradar) o emplear métodos sísmicos, para medir la totalidad del espesor de los glaciares.

En Chile central, la mayoría de los glaciares presentan menores dimensiones, con una topografía más compleja y agrietada, por lo que el uso de motos de nieve es poco apropiado. En estos casos, se ha empleado el mismo sistema de radar de perfilaje pero montado en antenas de fibra de vidrio que se transportan a pié. Este sistema ha permitido medir espesores continuos de hielo en los glaciares del Cerro Tapado (RIVERA et al. 2000), Juncal Norte y San Francisco (Fig. 1). En todos estos casos, se logró penetrar la totalidad del hielo, presentándose el máximo en la zona de ablación del glaciar Juncal Norte, donde se midió $225 \mathrm{~m}$ de espesor (Fig. 4).

Estas mediciones de espesor son fundamentales para la determinación del volumen de recursos hídricos existente en Chile, así como para la determinación de los cambios que han experimentado (adelgazamiento o engrosamiento).

\section{Cambios de espesor (adelgazamiento-} engrosamiento)

Sólo algunos glaciares del país han sido 
evaluados en términos de sus cambios de espesor. La mayoría están ubicados en el CHS, definiendo una fuerte tendencia de adelgazamiento (Tabla 9). Destacan los elevados valores de adelgazamiento para el glaciar Upsala y O'Higgins (Fig. 1), ambos en el margen oriental del CHS. En dichos glaciares, así como en el Tyndall, se presentan las series más largas de medición, constatándose que las tasas de adelgazamiento han aumentado en las últimas décadas. En el caso del glaciar Upsala, las altas tasas de adelgazamiento registradas en los noventa no pueden explicarse sólo por los incrementos de la temperatura, existiendo factores dinámicos, ligados a la reducción del flujo emergente en el frente terminal (NARUSE et al. 1997).

Uno de los casos más significativos de adelgazamiento en el CHS lo constituye el glaciar Dickson, ubicado en el extremo norte del Parque Nacional Torres del Paine, el cual produjo en el año 1982 una gran crecida en el lago Dickson, alcanzando el nivel de las aguas a más de 4 metros por sobre el nivel actual.

Esta crecida se habría producido por el vaciamiento de un lago proglacial, formado en la confluencia de los glaciares Dickson y Frías (Fig. 1) a través de un conducto subglacial, fenómeno conocido como jökulhlaup, debido a la fuerte ablación del hielo en la zona, generándose una importante cantidad de agua de fusión, que se vació violentamente a través de un túnel bajo el hielo, al costado del margen del glaciar Dickson con el cordón montañoso del Cerro Daudet (PEÑA y ESCOBAR 1983). Este proceso se ha vuelto a producir en $1987 \mathrm{y}$ en menor grado en otras ocasiones pero no con la magnitud de 1982.

Sólo el glaciar Pío XI presenta un engrosamiento en el período 1975-1995, lo que se habría generado por un reacomodo del perfil del glaciar, propio de un surging glacier (RIVERA and CASASSA 1999).

Otra excepción a esta tendencia de adelgazamientos, la constituye el glaciar Perito Moreno que ha mantenido una gran estabilidad tanto de su posición frontal, como de su topografía superficial, lo que se debería al efecto regulador de la tasa de desprendimientos en el lago Argentino y a la alta proporción del área de acumulación versus área de ablación (SKVARCA and NARUSE 1997).

\section{DISCUSION}

\section{Relación con cambios climáticos}

Considerando que la gran mayoría de los glaciares aquí descritos están retrocediendo, con tasas variables pero significativas, que el balance de masa acumulado es negativo y que los cambios de espesor detectados son negativos, lo más probable es que el factor climático sea la principal causa que explica dichos procesos. No obstante existen respuestas no climáticas, especialmente en surging glaciers o en glaciares con frentes desprendentes, particularmente el glaciar Pío XI, proceso que ha sido bien documentado para otras latitudes (MEIER and POST 1987; WARREN 1991; MANN 1986).

Este proceso de deglaciación, también está afectando en el norte a los glaciares tropicales (SCHUBERT 1992; PORTOCARRERO 1995; HASTENRATH and AMES 1995) y en el sur, también afecta a la península Antártica (VAUGHAN and DOAKE 1996; ROTT et al. 1996; OPPENHEIMER 1998), todo lo cual es generado por la tendencia de largo plazo de calentamiento atmosférico, que según JONES et al. (1986), fue de $0.5{ }^{\circ} \mathrm{C}$ para los últimos 100 años en el hemisferio sur.

\section{Aumento de Temperaturas}

En Chile, las tendencias de aumento de temperaturas han sido evaluadas por ROSENBLÜTH et al. (1997), detectando para el período 1933-1992, una tasa de calentamiento de 1.3 a $2.0^{\circ} \mathrm{C} 100$ años-1. Este calentamiento de la atmósfera ha tendido a acelerarse en las últimas tres décadas, con una tasa que prácticamente se ha duplicado en Punta Arenas, Antofagasta y especialmente en Punta Angeles (Fig. 1 y Tabla 10), que presentó $3.8^{\circ} \mathrm{C}$ 100 años - 1 en el período 1960-1992. Este calentamiento es especialmente significativo respecto de las temperaturas mínimas, donde Punta Angeles y Punta Arenas (Fig. 1), vuelven a mostrar los mayores valores.

No obstante lo anterior, el calentamiento no es observable en las estaciones Temuco-Puerto Montt (Tabla 10), donde se ha estimado un enfriamiento entre $1960-1992$ de $1.1{ }^{\circ} \mathrm{C} \quad 100$ años -1. Esta condición, parece no haber afectado positivamente a los glaciares regionales, puesto que ellos mantienen altas tasas de retroceso, lo que puede deberse a que 
el enfriamiento sólo afectó a la baja atmósfera, o que dichos glaciares son más sensibles a las precipitaciones.

Según VILLALBA (1994), las condiciones de inviernos secos en Chile central, típicos de años La Niña, están bien correlacionados con veranos fríos en el norte de Patagonia $\left(41^{\circ} \mathrm{S}\right)$, por 10 que la mayor frecuencia de eventos El Niño observada en las últimas décadas (principal responsable de anomalías pluviométricas positivas en Chile central), se traduciría en mayores temperaturas de verano y por ende más fusión, en los glaciares a la latitud de Puerto Montt (Fig. 1). De hecho, las tendencias de cambio en las temperaturas máximas de Puerto Montt (Tabla 10) en verano, son las únicas que no presentan valores negativos para esta estación (ROSENBLÜTH et al. 1997).

La tendencia de calentamiento observada en gran parte de Chile, es sustancialmente menor a la registrada en el lado occidental de la península Antártica (KING 1994), por lo que el mayor calentamiento de esa parte del planeta, debiera darse en la interfaz hielo marino océano (ROSENBLÜTH et al. 1997).

\section{Cambios en las precipitaciones}

Respecto de las precipitaciones, se observa una reducción en los últimos 100 años en el norte, centro y el sector austral de Chile. A pesar de ello, las tendencias de mediano y largo plazo son menos claras que las de las temperaturas, existiendo una gran variabilidad interanual de los montos, en estrecha relación con el fenómeno ENOS especialmente en Chile central.

En el Norte chico DOWNING et al. (1994) determinaron una reducción del $30 \%$ de las lluvias en La Serena para el presente siglo, lo que se ha traducido en una migración al sur de la isoyeta de $100 \mathrm{~mm}$ del orden de $0.4 \mathrm{~km}$ a- 1 , lo que necesariamente ha favorecido el retroceso de glaciares.

En Chile central, RUTLLANT and FUENZALIDA (1991) han confirmado la estrecha relación entre los fenómenos ENOS y las anomalías pluviométricas, con un aumento significativo de las lluvias en una fase negativa del Indice de Oscilación del Sur (SOI) y una disminución significativa de lluvias en fases positivas de SOI. Esta relación ha generado balances de masa positivos en el glaciar
Echaurren en años con presencia del fenómeno "El Niño, sin embargo la mayor frecuencia de eventos La Niña en los 90, ha fortalecido balances negativos.

Respecto de los montos anuales en el largo plazo, la Dirección General de Aguas (DGA 1999) ha detectado una clara tendencia de reducción de las precipitaciones durante este siglo para la estación Quinta Normal en Santiago, además de confirmar la reducción para La Serena (Fig. 1), lo que conduciría al generalizado retroceso de glaciares observado.

En Chile austral, ROSENBLÜTH et al. (1995) constató que las estaciones Evangelistas y Bahía Felix (Tabla 10 y Fig. 1), redujeron sus montos anuales en forma monotónica, en 1,000 y $1,400 \mathrm{~mm}$ respectivamente durante este siglo, lo que representa aproximadamente un $25 \%$ de disminución.

En Patagonia oriental, IBARZABAL et al. (1996) detectó una clara tendencia negativa en las precipitaciones de la estación más cercana al CHS en Lago Argentino (Tabla 10 y Fig. 1). No obstante lo anterior, se observan algunas tendencias positivas en las estaciones de la costa Atlántica más al norte, las que también muestran una mayor tasa de incremento de temperaturas.

\section{Anomalías pluviométricas}

Otras estaciones de la región austral de Chile, como Punta Arenas, Isla San Pedro, Cabo Raper, Puerto Aysén, Isla Guafo y Ancud (Tabla 10 y Fig. 1) no muestran una clara tendencia de disminución o aumento secular, pero sí presentan importantes ciclos con anomalías pluviométricas positivas (SANTANA 1984; ROSENBLÜTH et al. 1995; WARREN 1993; RIVERA and CASASSA 1999).

Entre dichas estaciones, destaca el ciclo con anomalías pluviométricas positivas ocurridas entre 1935-55 en Punta Arenas, Cabo Raper, San Pedroe Isla Guafo, y el ciclo de anomalías positivas de la década de los 70 , en las estaciones Ancud, Puerto Aysén, Cabo Raper e Isla San Pedro (Tabla 10 y Fig. 1).

La ocurrencia de estas anomalías ha sido relacionada con las variaciones de glaciares, detectándose que hay una clara vinculación entre avances frontales, con ciclos de anomalías 
ANEXo 1

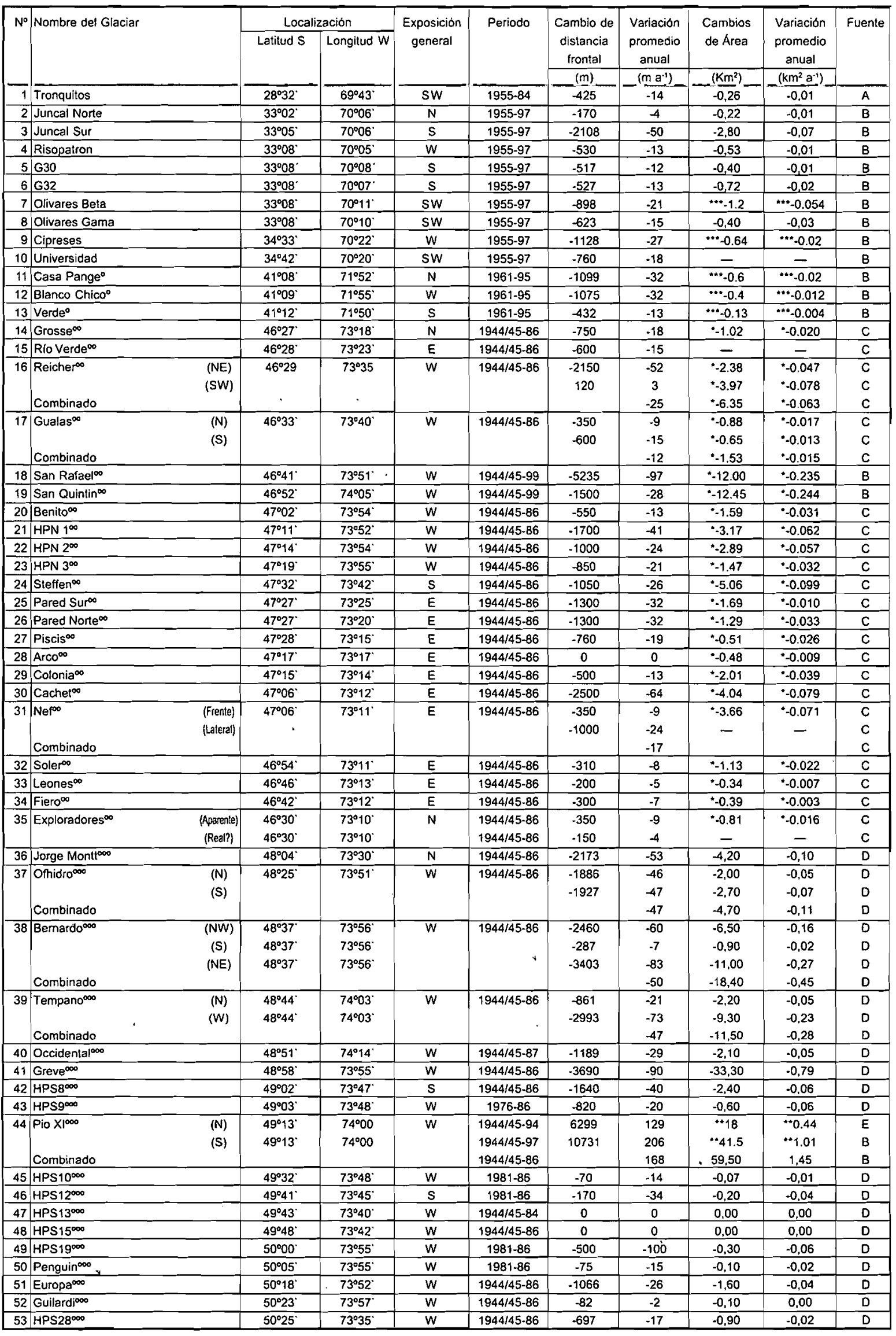


ANEXO 1, CONTINUACION

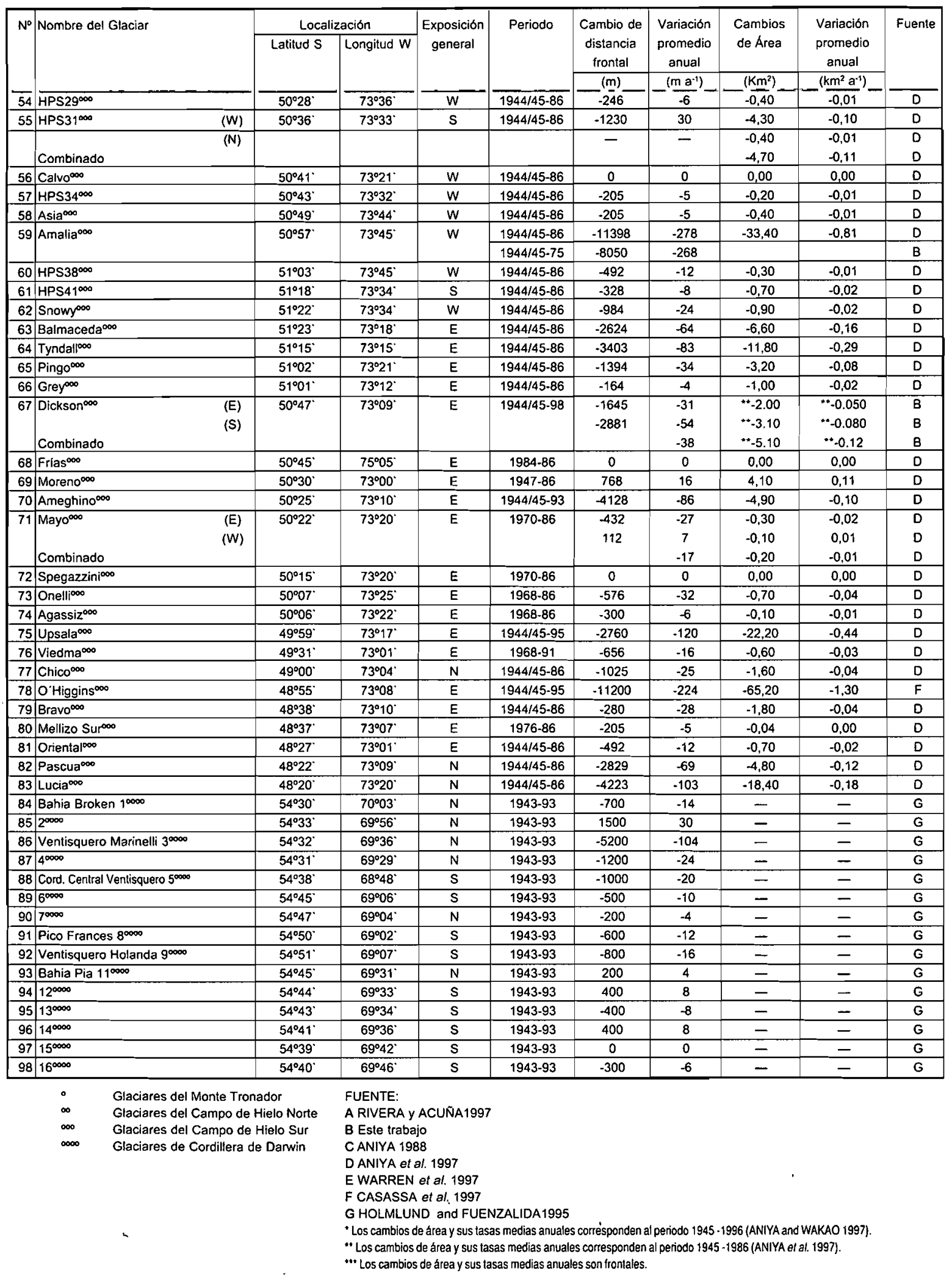

\section{Variaciones de glaciares en Chile.}

1. Glacier variations in Chile. 
pluviométricas positivas, separados por un tiempo de respuesta que en el CHN fue estimado en 15 a 20 años (WINCHESTER and HARRISON 1996) y en el CHS fue estimado en 10 a 25 años (RIVERA et al. 1997b).

De esta forma, como respuesta a las anomalías pluviométricas de 1935-1955, se habrían producido avances en la década del 40 y 50 de los glaciares San Quintín, (WINCHESTER and HARRISON 1996), San Rafael (WARREN 1993) y Pío XI (RIVERA et al. 1997a), así como repetidos embalsamientos del brazo Rico de] lago Argentino, generados por el avance del glaciar Perito Moreno (NICHOLS and MILLER 1952; ANIYA and SKVARCA 1992).

De la misma forma, el avance del glaciar Pío XI en la década de los 90 (RIVERA et al. 1997a), el estancamiento en el retroceso e indicios de leve avance del San Rafael a principios de los 90 (WARREN 1993) y un leve avance del San Quintín entre 1991 y 1993 (WINCHESTER and HARRISON 1996), también podrían estar relacionados con el ciclo de anomalías pluviométricas positivas de la década de los 70 .

Para el CHN, ANIYA and ENOMOTO (1986) concluyeron que anomalías pluviométricas positivas resultan en avances de glaciares.

\section{¿Porqué estas anomalías no afectaron a todos los glaciares de la zona?}

Estos avances excepcionales y asincrónicos, evidencian que las respuestas de los glaciares son complejas y no dependen exclusivamente del clima, sino que de una combinación de factores climáticos (temperaturas, precipitaciones, líneas de nieve, etc.), factores topográficos (hipsometría de las cuencas, geometría de los valles, amplitud altimétrica, etc.) y factores glaciodinámicos (velocidades del hielo, ciclos de calving, surges, etc.), donde cada glaciar tiene sensibilidades diferenciales.

Este tipo de respuestas asincrónicas son especialmente relevantes en Patagonia, donde predominan los frentes desprendentes, grandes superficies de acumulación y un fuerte contraste marítimo-continental.

Por ejemplo en el caso del glaciar Pío XI, RIVERA and CASASSA (1999), han confirmado que los aumentos de altura experimentados por la línea de equilibrio de este glaciar entre 1944 y 1995 , se han producido en una zona de gran pendiente en la hipsometría de la cuenca glaciar, por lo que no ha habido un cambio significativo de AAR (acumulation area ratio), haciéndolo prácticamente insensible a los aumentos de temperaturas, sin embargo las anomalías pluviométricas positivas, han impactado significativamente el glaciar, explicando los avances.

En el caso del glaciar Upsala (ANIYA and SKVARCA 1992; NARUSE et al. 1995), se ha constatado que los cambios de altura de la línea de equilibrio se dan en una zona con escasa pendiente, lo que estaría provocando un significativo cambio del AAR de este glaciar, detonando su fuerte retroceso.

En Chile norte, centro y sur hasta Chiloé continental, los glaciares presentan una topografía compleja, con fuertes pendientes y frentes terminales normales sin desprendimientos de témpanos, salvo contadas excepciones, donde debido al fuerte retroceso que han experimentado, unos pocos glaciares presentan desprendimiento de témpanos en pequeñas lagunas proglaciales, como por ejemplo el glaciar Morado y Olivares Gama (Fig. 1).

Estas condiciones, los hacen responder en forma más directa y sincrónica, a las variaciones climáticas observadas, generándose una respuesta prácticamente única, sin excepciones.

Respecto de las sensibilidades específicas de cada glaciar, WARREN and SUGDEN (1993), han planteado que los glaciares occidentales de Patagonia son más sensibles a cambios en las precipitaciones, mientras que los orientales lo serían más a las temperaturas. De igual forma, KERR and SUGDEN (1994), plantean que las variaciones altitudinales de la línea de nieves entre los $46^{\circ} \mathrm{S}$ y $50^{\circ} \mathrm{S}$, serían más dependientes de las temperaturas, mientras que al norte de los $46^{\circ} \mathrm{S}$ y al sur de los $50^{\circ} \mathrm{S}$, serían más sensibles a las precipitaciones.

Considerando que la tendencia de las temperaturas ha sido a su incremento en casi todo el país y que la tendencia de las precipitaciones ha sido a su disminución con alta variabilidad interanual en Chile central y en Patagonia Austral, es esperable que la tendencia de retrocesos continúe, afectando a todo el país. 


\section{CONCLUSIONES}

Las variaciones recientes de los glaciares de Chile indican que hay un proceso de deglaciación en curso, el cual está afectando todo el país, con mayor énfasis en Patagonia desde el punto de vista del aporte en volumen equivalente en agua, pero más importante en Chile central por el porcentaje de pérdida de superficie de hielo.

Las consecuencias globales de esta pérdida de superficie, adelgazamiento y retroceso, pueden ser analizadas desde el punto de vista del aporte al aumento del nivel del mar, donde se estima que los glaciares de Chile podrían aportar cerca del $10 \%$ del total aportado por los glaciares de montaña del planeta.

Los Campos de Hielo Patagónicos siguen siendo las principales áreas englaciadas del país, sin embargo aún quedan numerosas incógnitas por resolver, como los espesores reales, los adelgazamientos en las zonas de acumulación y los balances de masa.

Los glaciares de Chile central, si bien tienen una baja participación en el aporte volumétrico a nivel global, son vitales para la mantención de caudales en zonas pobladas en períodos con veranos secos, especialmente frente a la mayor frecuencia de eventos ENOS extremos.

Las glaciares del norte del país no han merecido la suficiente atención de los especialistas, lo que debiera revertirse en el futuro, especialmente respecto a los glaciares rocosos.

Las tendencias de aumentos de temperatura y descenso de precipitaciones verificadas en el país, seguirán afectando negativamente a los glaciares de los Andes, por lo que la evaluación detallada de sus respuestas y tendencias futuras es una tarea glaciológica prioritaria.

\section{AGRADECIMIENTOS}

Este trabajo es parte del proyecto del Fondo Nacional de Ciencias y Tecnología (FONDECYT) N ${ }^{\circ}$ 1980293. Se agradece la colaboración de Roberto Smith en la confección de cartas y figuras. Carlos Cárdenas y Rubén
Carvallo, han colaborado permanentemente con el diseño y mantención del sistema de radar. Jorge Quinteros de la Dirección General de Aguas, ha sido nuestro logístico y montañista durante todas nuestras expediciones. Se agradece la colaboración y financiamiento de la Facultad de Arquitectura y Urbanismo de la Universidad de Chile, para la realización de campañas de terreno a los glaciares de Chile Central. La Fuerza Aérea de Chile, otorgó su apoyo logístico en las campañas Hielo Azul dirigidas al Campo de Hielo Sur y en el glaciar Tyndall. La Alta Montaña del Ejército de Chile, efectuó el apoyo logístico en las campañas del glaciar Juncal Norte. Carabineros de Chile, ofreció su apoyo logístico para acceder al glaciar Pío XI. La Corporación Nacional Forestal, facilitó el acceso al parque nacional Torres del Paine y Bernardo O'Higgins, así como al monumento natural El Morado, colaborando con la logística de estudios en los glaciares San Francisco, Tyndall, Dickson y Grey. El Instituto Antártico Chileno, en particular su director Dn. Oscar Pinochet de la barra y el Ing. Víctor Villanueva, facilitaron instrumentos para terreno. Se agradece a Fernando Escobar, Carlos Garín y Guillermo Tapia de la Dirección General de Aguas, por el acceso a los datos del glaciar Echaurren, fotos aéreas y cartografía de glaciares de Chile Central.

\section{REFERENCIAS}

AGOSTINI, A., 1945. Andes Patagónicos. Viajes de Exploración a la Cordillera Patagónica Austral. Talleres gráficos de Guillermo Kraft, Buenos Aires.

ANIYA, M., 1988. Glacier Inventory for the Northern Patagonia Icefield, Chile, and Variations 1944/45 to 1985/86. Arctic and Alpine Research, 20: 179-187.

ANIYA, M. 1999. Recent Glacier Variations of the Hielos Patagónicos, South America, and their Contribution to Sea-level Change. Arctic and Alpine Research 31(2): 165-173.

ANIYA, M. and H. ENOMOTO, 1986. Glacier Variations and their Causes in the Northern Patagonia Icefield, Chile, since 1944. Arctic and Alpine research, 18(3): 307-316.

ANIYA, M and R. NARUSE, 1987. Structural and Morphological Characteristics of Soler 
Glacier, Patagonia. Bulletin of Glacier Research, 4: 69-77.

ANIYA, M. and P. SKVARCA, 1992. Characteristics and Variations of Upsala and Moreno glaciers, Southern Patagonia. Bulletin of Glacier Research, 10: 39-53.

ANIYA, M., H. SATO, R. NARUSE, P. SKVARCA and G. CASASSA, 1996. The Use of Satellite and Airborne Imagery to Inventory Outlet Glacier of the Southern Patagonia Icefield, South America. Photogrammetric Engineering and Remote Sensing, 62: 1361-1369.

ANIYA, M., H. SATO, R. NARUSE, P. SKVARCA and G. CASASSA, 1997. Recent Variations in the Southern Patagonia Icefield, South America. Arctic and Alpine Research, 29: $1-12$.

ANIYA, M. and Y. WAKAO, 1997. Glacier Variations of Hielo Patagónico Norte, Chile, Between 1944/45 and 1995/96. Bulletin of Glacier research 15: 11-18.

ANIYA, M., R. NARUSE, G. CASASSA and A. RIVERA, 1998. Variations of Patagonian Glaciers, South America, Utilizing RADARSAT Images. Radarsat Symposium, Canada.

ARISTARAIN, A. and R. DELMAS, 1993. Firn-core Study from the Southern Patagonia ice cap, South America. Journal of Glaciology 39(132): 249-254.

BRÜGGEN, J., 1950. Fundamentos de la Geología de Chile. Instituto Geográfico Militar, Santiago.

CASASSA, G., 1987. Ice Thickness Deduced from Gravity Anomalies on Soler Glacier, Nef Glacier and the Northern Patagonia Icefield. Bulletin of Glacier Research, 4: 43-57.

CASASSA, G., 1992. Radio-echo Sounding of Tyndall Glacier, Southern Patagonia. Bulletin of Glacier Research, 10: 69-74.

CASASSA, G. 1995. Glacier Inventory in Chile: Current Status and Recent Glacier Variations. Annals of Glaciology 21: 317-322.

CASASSA, G., H. BRECHER, A. RIVERA and M. ANIYA, 1997. A Century-long Record of Glaciar O'Higgins, Patagonia. Annals of Glaciology, 24:106-110.
CASASSA, G., L. ESPIZÚA, B. FRANCOU, P. RIBSTEIN, A. AMES and J. ALEAN, 1998a. Glaciers in South America. In: Into the second century of World Wide glaciers Monitoring: Prospects and Strategies. HAEBERLI, HOELZE AND SUTER (Eds.) World Glacier Monitoring Service. Studies and Reports in Hydrology, Zürich: 56:125-146.

CASASSa, G., R. CARVallo, C. CÁRDENAS, B. JELINIC, and A. RIVERA, 1998b. Performance of a Snowmobile-Based radio Echo Sounding System at Patriot Hills, Antarctica. In: Proceedings VIII SCALOP Symposium, Santiago: 93-101.

CASASSA, G. and A. RIVERA, 1998. Digital Radio-Echo Sounding at Tyndall Glacier, Patagonia. Anales del Instituto de la Patagonia, Ser. Cs. Nat., 26:129-135.

CASASSA, G. and A. RIVERA, (submitted). Topographic Mass Balance Model for the Southen Patagonia Icefield. Annals of Glaciology.

CAVIEDES, J. 1979. Inventario de Glaciares en la Hoya del río Cachapoal y Predicción de la Escorrentía del Deshielo. Andes Centrales. Universidad de Chile, Departamento de Geología.

CORTE, A., 1998. Rock Glaciers. In: Williams R. and J. Ferrigno (Eds.) Satellite Image Atlas of Glaciers of the World. Glaciers of South America-Glaciers of Chile and Argentina.. USGS 1386-I: 1136-1147.

DGA (DIRECCION GENERAL DE AGUAS), 1995. Balance de Masa en el Glaciar Echaurren Norte 1975-1982. Resultados Preliminares. Publicación No 95/1.

DGA, 1997. Complemento $\mathrm{N}^{\circ} 1$, años 19931996, a la publicación: "Balance de masa en el Glaciar Echaurren Norte 1975-1982. Resultados Preliminares". Publicación N ${ }^{\circ}$ 97/1.

DGA, 1999. Política Nacional de Recursos Hídricos. Documento de Discusión. Ministerio de Obras Públicas/Dirección General de Aguas.

DOWNING, T., F. SANTIBAÑEZ, H. ROMERO, H. PEÑA, R. GWYNE, M. IHL and A. RIVERA, 1994. Climate Change and Sustainable Development in the Norte Chico, Chile: Climate, Water Resources and Agricul- 
ture. Occasional paper $\left(\mathrm{N}^{\circ} 35\right)$ of the School of Geography, University of Birmingham and Research Report $\left(\mathrm{N}^{\circ} 6\right)$ of the Environmental Change unit, University of Oxford.

DREWRY, D. 1975. Comparison of Electromagnetic and Seismic-Gravity Ice Thickness Measurements in East Antarctica. Journal of Glaciology, 15(73):137-50.

ESCOBAR, F, G. CASASSA and V. POZO, 1995. Variaciones de un Glaciar de Montaña en los Andes de Chile Central en las últimas dos décadas. Bulletin de l'Institut Francais d'Études Andines 24(3): 683-695.

ESPIZÚA, L. y C. AGUADO, 1984. Inventario de Glaciares y Morenas entre los $29^{\circ}$ y $35^{\circ}$ de lat. sur, Argentina. In: Jornadas de Hidrología de Nieves y Hielos en América del sur. Programa Hidrológico Internacional, Santiago 1: 7.1-7.17.

FORSTER, R. 1997. Synthetic Aperture Radar (SAR) Observations of Calving Glaciers. In: C. Van Der Veen (Ed,) Byrd Polar Researh Center Report, , The Ohio State University, Columbus 15: 71-76.

FORSTER, R., B. ISACKS. and D. DAS, 1996. Shuttle Imaging Radar (SIR-C/X-SAR) Reveals Near-surface Properties of the south Patagonian ice-field. Journal of Geophysical Research, 101(E10): 23169-23180.

FORSTER, R., L. SMITH and B. ISACKSC, 1997. Effects of Weather Events on X-SAR Returns from Ice Fields: Case-Study of Hielo Patagónico Sur, South America. Annals of Glaciology, 24: 367-374.

FORSTER, R., E. RIGNOT, B. ISACKS and K. JEZEK, 1999. Interferometric Radar Observations of Glaciares Europa and Penguin, Hielo Patagónico Sur, Chile. Journal of Glaciology, 45(150): $325-337$.

FRANCOU, B., P. RIBSTEIN, H. SÉMIOND, C. PORTOCARRERO and $A$. RODRÍGUEZ, 1995. Balances de Glaciares y Clima en Bolivia y Perú: Impacto de los Eventos ENSO. Bulletin de l'Institut Francais d'Études Andines 24(3): 661-670.

FRANCOU, B. and J. SICART, 1999. Response of Tropical Glaciers to the Climatic
Variability during the last Decades of the 20th Century: Zongo, Chacaltaya $\left(16^{\circ} \mathrm{S}\right)$ and Antizana Glaciers $\left(0^{\circ}\right)$, central Andes. In: Abstracts International Symposium on the Verification of Cryospheric Models: Bringing data and Modelling scientists together. Zürich: 6 .

GARÍN, C. 1987. Inventario de Glaciares de los Andes Chilenos desde los $18^{\circ}$ a los $32^{\circ}$ de latitud sur. Revista de Geografía Norte Grande, 14: $35-48$.

GILBERT, J., M. STASIUK, S. LANE, C. ADAM, M. MURPHY, S. SPARKS and J. NARANJO, 1996. Non-explosive, Constructional Evolution of the Ice-filled Caldera at Volcán Sollipulli, Chile. Bulletin of Volcanology 58: 67-83.

GROSJEAN, M., B. MESSERLI and H. SCHREIER, 1991. Seenhochstände, Bodenbildung und Vergletscherung im Altiplano Nordchiles: Ein interdisziplinärer Beitrug zur Klimageschichte der Atacama. Erste Resultate. Bamberger Geographische Schiriften 11:99-108.

HAEBERLI, W., 1998. A strategy for Monitoring Climate Change Using a Network of Glaciers. World Glacier Inventory Report, WGMS, Zürich.

HEUSSER, C., 1960. Late-Pleistocene Environments of the Laguna de San Rafael area, Chile. The Geographical Review, L(4): 555577.

HASTENRATH, A. and A. AMES, 1995. Recession of Yanamarey Glacier in Cordillera Blanca, Perú, during the 20th century. Journal of Glaciology 41(137): 191-196.

HOLMLUND, P. and H. FUENZALIDA, 1995. Anomalous Glacier Responses to 20th Century Climatic Changes in Darwin Cordillera, Southern Chile. Journal of Glaciology 41(139): 465-473.

HULTON, R. and D. SUGDEN, 1995. Modelling Mass Balance on Former Maritime Ice Caps: a Patagonian example. Annals of Glaciology, 21: 304-310. 
IAHS/UNESCO (INTERNATIONAL ASSOCIATION OF HYDROLOGICAL SCIENCES / UNITED NATIONS EDUCATIONAL SCIENTIFIC and CULTURAL ORGANIZATION), 1994. Glacier Mass Balance Bulletin $N^{\circ}$ 3. (1992-1993). World Glacier Monitoring Service, Zürich.

IAHS/UNESCO, 1996. Glacier Mass Balance Bulletin $\mathrm{N}^{\circ} 4$. (1994-1995). World Glacier Monitoring Service, Zürich.

IAHS/UNESCO, 1998. Fluctuations of Glaciers 1990-1995. Volume VII, World Glacier Monitoring Service Zürich.

IAHS/UNESCO, 1999. Glacier Mass Balance Bulletin N5. (1996-1997). World Glacier Monitoring Service, Zürich.

IBARZABAL, T., T. DONÁNGELO, J. HOFFMANN and R. NARUSE, 1996. Recent Climate Changes in Southern Patagonia. Bulletin of Glacier Research, 14: 29-36.

IWATA, S., 1983. Further Advance of Pío XI glacier. In: R. Naruse (Ed.). Glaciological and Meteorological Studies in Patagonia, Chile by Japanese research Expeditions in 1967-1982. Data center for Glacier Researches, Japanese Society of Snow and Ice, Japan: 14-17.

JENNY, B. and K. KAMMER, 1996. Jungquartäre Vergletscherungen. In: Climate Change in den Trockenen Anden. Geographica Bernensia G46, Berna:1-80.

JONES, P., S. RAPER and T. WIGLEY, 1986. Southern Hemisphere Surface Air Temperature Variations: 1851-1984. Journal of Climate and Applied meteorology, 25: 1213-1230.

KADOTA, T., R. NARUSE, P. SKVARCA and M. ANIYA, 1992. Ice Flow and Surface lowering of Tyndall Glacier, Southern Patagonia. Bulletin of Glacier Research, 10:6368.

KERR, A. and D. SUGDEN, 1994. The sensitivity of the South Chilean Snowline to Climatic Change. Climatic Change, 28: 255-272.

KING, J., 1994. Recent Climate Variability in the Vicinity of the Antarctic Peninsula. International Journal of Climatology, 14: 357-369.
KONDO, H. and T. YAMADA, 1988. Some Remarks on the Mass Balance and the Terminal-lateral Fluctuations of San Rafael, the Northern Patagonia Icefield. Bulletin of Glacier Research, 6: 55-63.

LEIVA, J. and G. CABRERA, 1996. Glacier Mass Balance Analysis and Reconstruction in the Cajón del Rubio, Mendoza, Argentina. Zeitschrift fur Gletscherkunde und Glazialgeologie, 32: 101-107.

LLIBOUTRY, L.,1956. Nieves y Glaciares de Chile. Fundamentos de Glaciología. Ediciones de la Universidad de Chile, Santiago.

LLIBOUTRY, L., O. GONZÁLEZ and J. SIMKEN, 1958. Les Glaciers du Desert Chilien. In: Extrait des Comptes Rendus et Rapports. Assemblee Generale de Toronto, Tome IV: 291-300.

LLORENS, R. and J. LEIVA, 1995. Glaciological studies in the High Central Andes Using Digital processing of Satellite Images. Mountain Research and Development, 15(4): 323-330.

MANN, D., 1986. Reliability of a Fjord Glaciers's Fluctuations for Paleoclimatic Reconstructions. Quaternary Research, 25: 10-24.

MATSUOKA, K., R. NARUSE, Y. KITAMORI and K. OGAWA, 1998. FirnCore drilling, Hielo Patagónico Norte (HPN). Ice, 116: 6.

MATSUOKA, K. and R. NARUSE, 1999. Mass Balance Features Derived from a Firn Core at Hielo Patagónico Norte, South America. Arctic, Antarctic and Alpine Research, 31(4):333-340.

MARANGUNIC, C. 1979. Inventario de Glaciares. Hoya del río Maipo. Dirección General de Aguas, Publicación G-2, Santiago.

MEIER, M. 1984. Contribution of Small Glaciers to Global Sea Level. Science, 226: 1418 1420.

MEIER, M. and A. POST, 1987. Fast Tidewater Glacier. Journal of Geophysical Research, 92(B9): 9051-9058. 
MESSERLI, B., M. GROSJEAN, G. BONANI, A. BÜRGI, M. GEYH, K. GRAF, K. RAMSEYER, H. ROMERO, U. SCHOTTERER, H. SCHEREIER and $M$. VUILLE, 1993. Climate Change and Natural Resources Dynamics of the Atacama Altiplano During the Last 18,000 years: A preliminary Synthesis. Mountain Research and Development, 13(2):117-127.

MESSERLI, B., C. AMMANN, M. GEYH, M. GROSJEAN, B. JENNY, K. KAMMER and M. VUILLE, 1998. The Problem of the "Andean Dry Diagonal": Current Precipitation, Late Pleistocene Snow Line, and Lake Level Changes in the Atacama Altiplano $\left(18^{\circ} \mathrm{S}-28^{\circ} \%\right.$ $29^{\circ} \mathrm{S}$ ). Bamberger Geographische Schriften, 15:17-34.

MICHEL, R. and E. RIGNOT, 1999. Flow of Glaciar Moreno, Argentina, from repeat-pass Shuttle Imaging Radar Images: Comparison of the Phase Correlation Method with Radar Interferometry. Journal of Glaciology, 45(149), 93-100.

MORENO, H. and G. FUENTEALBA, 1994. The May 17-19 1994 Llaima Volcano Eruption, Southern Andes ( $38^{\circ} 42^{\prime}$ S- $\left.71^{\circ} 44^{\prime} W\right)$. Revista Geológica de Chile 21(1): 167-171

MURDIE, R., D. PRIOR, P. STYLES, S. FLINT, R. PEARCE and S. AGAR, 1993. Seismic Responses to Ridge-Transform Subduction: Chile Triple Junction. Geology, 21: 1,0951,098 .

NARANJO, J., H. MORENO and N. BANKS, 1993. La Erupción del Volcán Hudson en 1991 (46 $\left.{ }^{\circ} \mathrm{S}\right)$, Región XI, Aysén, Chile. Servicio Nacional de Geología y Minería-Chile, Boletín $\mathrm{N}^{\circ} 44$, Santiago.

NARUSE, R., 1985. Flow of Soler and San Rafael Glacier. In: Glaciological Studies in Patagonia Northern Icefield. Data Center for Glacier Research, Japanese Society of Snow and Ice, Japan: 64-69.

NARUSE, R., 1987. Characteristics of Ice Flow of Soler Glacier, Patagonia. Bulletin of Glacier Research, 4: 79-85.

NARUSE, R., H. PEÑA, M. ANIYA and J. INOUE, 1987. Flow and Surface Structure of Tyndall Glacier, the Southern Patagonia Icefield. Bulletin of Glacier Research 4: 133140.
NARUSE, N. and M. ANIYA, 1992. Outline of Glacier Research in Patagonia, 1990. Bulletin of Glacier Research 10: 31-38.

NARUSE, R., P. SKVARCA, T. KADOTA and K. KOIZUMI, 1992a. Flow of Upsala and Moreno glaciers, Southern Patagonia. Bulletin of Glacier Research 10: 55-62.

NARUSE, R., H. FUKAMI and M. ANIYA, 1992b. Short-term Variations in Flow Velocity of Glaciar Soler, Patagonia, Chile. Journal of Glaciology, 38(128):152-156.

NARUSE, R., M. ANIYA, P. SKVARCA and G. CASASSA, 1995. Recent Variations of Calving Glaciers in Patagonia, South America, Revealed by Ground Surveys, Satellite-data Analyses and Numerical Experiments. Annals of Glaciology, 21: 297-303.

NARUSE, R., P. SKVARCA and Y. TAKEUCHI, 1997. Thinning and Retreat of Glaciar Upsala, and an estimate of annual ablation Changes in Southern Patagonia. Annals of Glaciology, 24: 38-42.

NICHOLS, R. and M. MILLER, 1952. Advancing glaciers and nearby simultaneously retreating glaciers. Geographical Review, 41:274294.

NISHIDA, K., K. SATOW, M. ANIYA, G. CASASSA and T. KADOTA, 1995. Thickness Change and Flow of Tyndall Glacier, Patagonia. Bulletin of Glacier Research, 13: 29-34.

NOVEROY, C. 1987. Inventario de Glaciares de la hoya del río Mataquito. Dirección general de Aguas, Publicación Interna, EH 87/1, Santiago.

OPPENHEIMER, M., 1998. Global Warming and the Stability of the West Antarctic Ice Sheet. Nature, 393:325-332.

PATERSON, W., 1994. The Physics of Glaciers. Pergamon Press, London.

PEÑA, H. y F. ESCOBAR, 1983. Análisis de las Crecidas del Río Paine, XII Región. Publicación Interna $\mathrm{N}^{\circ} 83 / 7$, Estudios Hidrológicos, Departamento Hidrología, DGA, Santiago. 
PEÑA, H. y F. ESCOBAR, 1987. Análisis del Aluvión de Mayo de 1985 del río Manflas cuenca del río Copiapó. Publicación Interna $\mathrm{N}^{\circ}$ 87/3 Estudios Hidrológicos, Departamento de Hidrología, DGA, Santiago.

PEÑA, H. and N. NAZARALA, 1987. Snowmelt-runoff Simulation Model of a Central Chile Andean Basin with Relevant Orographic Effects. In: Large Scale Effects of Seasonal Snow Cover (Proceedings of the Vancouver Symposium) IAHS Publ. 166: 161-172.

PORTOCARRERO, C., 1995. Retrocesos de Glaciares en el Perú: Consecuencias sobre los Recursos Hídricos y los Riesgos Geodinámicos Bulletin de l'Institut Francais d'Études Andines 24(3): 697-706.

RIBSTEIN, P., E. TIRIAU, B. FRANCOU and R. SARAVIA, 1995. Tropical Climate and Glacier Hydrology: A case Study in Bolivia. Journal of Hydrology, 165: 221-234.

RIGNOT, E., R. FORSTER and B. ISACKS, 1996a. Mapping of Glacial Motion and Surface Topography of Hielo Patagónico Norte, Chile, Using satellite SAR L-Band Interferometry data. Annals of Glaciology 23: 209216.

RIGNOT, E., R. FORSTER and B. ISACKS, 1996b. Interferometric radar observations of Glaciar San Rafael, Chile. Journal of Glaciology 42(141): 279-291.

RISOPATRON, L., 1905. La Cordillera de los Andes, entre las latitudes $46^{\circ}$ I $50^{\circ} \mathrm{s}$. Imprenta Cervantes, Santiago.

RIVERA, A. 1989. Inventario de Glaciares entre las cuencas de los ríos Bio Bio y Petrohué. Su relación con el volcanismo activo: Caso Volcán Lonquimay. Memoria de Título, escuela de Geografía, Universidad de Chile, Santiago.

RIVERA, A., 1992. El Glaciar Pío XI: Avances y Retrocesos, el impacto sobre su entorno durante el presente siglo. Revista Geográfica de Chile Terra Australis, 36: 33 - 62.

RIVERA, A., J. ARAVENA and G. CASASSA, 1997a. Recent Fluctuations of Glaciar Pío XI, Patagonia: Discussion of a Glacial Surge Hypothesis. Mountain Research and Development, 17(4): 309-322.
RIVERA, A., H. LANGE, J. ARAVENA and G. CASASSA, 1997b. The 20th Century Advance of Glaciar Pío XI, Southern Patagonia Icefield. Annals of Glaciology, 24: 66-71.

RIVERA, A. y C. ACUÑA, 1997. Variaciones recientes de Glaciares en la macrozona central de Chile. XVIII Congreso Nacional de Geografía. Sociedad Chilena de Ciencias Geográficas, Santiago, 293-304.

RIVERA, A. and G. CASASSA, 1999. Volume Changes of Pio XI Glacier:1975-1995. Global Planetary Change 22(1-4):233-244.

RIVERA, A., G. CASASSA, R. CARVALlo and H. LANGE, 1998. Complex Subglacial Topography Revealed Under The Antarctic Ice Sheet at Patriot Hills. In: Abstracts Antarctic Geodesy Symposium, U. de Chile, Santiago.

RIVERA, A., A. GIANNINI, J. QUINTEROS and M. SCHWIKOWSKI, 2000. Ice thickness measurements on the glacier of Cerro Tapato, Norte Chico, Chile. In: Annual Report 1999, Labor für Radio-Und Umweltchemie der Universität Bern und des Paul Scherrer Instituts, Switzerland, Villigen: 38.

ROTT, H., P. SKVARCA and T. NAGLER, 1996. Rapid Collapse of Northern Larsen Ice Shelf, Antarctica. Science, 271: 788-792.

ROTT, H., M. STUEFER, A. SIEGEL, P. SKVARCA. and A. ECKSTALLER, 1998. Mass fluxes and dynamics of Moreno Glacier, Southern Patagonia Icefield. Geophysical Research Letters, 25(9): 1407-1410.

ROSENBLÜTH, B., G. CASASSA and H. FUENZALIDA, 1995. Recent climate changes in Western Patagonia. Bulletin of Glacier Research, 13: 127-132.

ROSENBLÜTH, B., H. FUENZALIDA and P. ACEITUNO, 1997. Recent Temperature Variations in Southern South America. International Journal of Climatology, 17: 67-85.

RUTLLANT, J. and H. FUENZALIDA, 1991. Synoptic aspects of the Central Chile rainfall variability associated with the Southern Oscillation. International Journal of Climatology, 11:63-76. 
SANTANA, A., 1984. Variación de las precipitaciones de 97 años en Punta Arenas como índice de posibles cambios climáticos. Anales del Instituto de la Patagonia, Ser. Cs. Nat., 15:5]-60.

SCHUBERT, C., 1992. The Glaciers of the Sierra Nevada de Mérida (Venezuela): A Photographic Comparison of Recent Deglaciation. Erkunde, 46: 58-64.

SCHWIKOWSKI, M., P. GINOT, M. FUNK, H. GÄGGELER, S. HÜBENER, B. POUYAUD, U. SCHOTTERER and W. STINCHLER, 1999. Palaleo Atmospheric Chemistry and Precipitation Climatology from Cerro Tapado Ice Core, Chile. In: Sixth International Global Atmospheric Chemistry Conference, Atmospheric Chemistry-Climate Interactions. Bologna, Poster Session 4.

SKVARCA, P., K. SATOW, R. NARUSE and J. LEIVA, 1995. Recent thinning, retreat and flow of Upsala Glacier, Patagonia. Bulletin of Glacier Research 13: 11-20.

SKVARCA, P. and R. NARUSE, 1997. Dynamic Behavior of Glaciar Perito Moreno, Southern Patagonia. Annals of Glaciology, 24: 268-271.

VALDIVIA, P. 1984. Inventario de Glaciares, Andes de Chile Central $\left(32^{\circ}-35^{\circ}\right.$ lat. S). Hoyas de los ríos Aconcagua, Maipo, Cachapoal y Tinguiririca. In: Jornadas de Hidrología de Nieves y Hielos en América del Sur. Programa Hidrológico lnternacional, Santiago de Chile 1: 6.1-6.24.

VAN DER VEEN, C., 1996. Tidewater calving. Journal of Glaciology 42(141): 375-385.

VAUGHAN, D. and C. DOAKE, 1996. Recent Atmospheric warming and retreat of Ice Shelves on the Antarctic Peninsula. Nature, 379:328-330.

VILLALBA, R., J. LEIVA, S. RUBULLS, J. SUAREZ and L. LENZANO, 1990. Climate, Tree-Ring, and Glacial Fluctuations in the Río Frías Valley, Río Negro, Argentina. Arctic and Alpine research, 22(3): 215-232.

VILLALBA, R., 1994. Tree-ring and Glacial Evidence for the Medieval Warm Epoch and the Little Ice Age in Southern South America. Climatic Change, 26:183-197.
WADA, Y. and M. ANIYA, 1995. Glacier Variations in the Northern Patagonia Icefield between 1990/91 and 1993/94. Bulletin of Glacier Research 13: 111-119.

WARREN, C., 1991. Terminal Environment, Topographic Control and Fluctuations of West Greenland Glaciers. Boreas 20: 1-15.

WARREN C. 1993. Rapid Recent Fluctuations of the Calving San Rafael Glacier, Chilean Patagonia: Climatic or Non-Climatic?. Geografiska Annaler, 75A(3): 111-126.

WARREN, C. and A. RIVERA, 1994. Non?linear Climatic Response of Calving Glaciers: A case study of Pío XI Glacier, Chilean Patagonia. Rev. Chilena de Historia Natural, 67: 385?394.

WARREN, C. and D. SUGDEN, 1993. The Patagonian Icefields: A Glaciological Review. Arctic and Alpine Research, 25(4): 316-331.

WARREN, C., N. GLASSER, A. KERR, S. HARRISON, V. WINCHESTER and A. RIVERA, 1995. Calving Activity at the Tidewater San Rafael Glacier, Chile. Journal of Glaciology, 41(138):273?289.

WARREN, C., A. RIVERA and A. POST, 1997. Greatest Holocene advance of Glaciar Pío XI, Chilean Patagonia: Possible Causes. Annals of Glaciology, 24: 11-15.

WINCHESTER, V. and S. HARRISON, 1996. Recent Oscillations of the San Quintín and San Rafael Glaciers, Patagonian Chile. Geografiska Annaler 78A(1): 35-50.

WINCHESTER, V. and S. HARRISON, 1997 Estimate of ice-surface velocity over a 4 year period on Glaciar Arenales, Hielo Patagónico Norte, Chile. Journal of Glaciology, 43(144): 370-371.

YAMADA, T., 1987. Glaciological Characteristics Revealed by $37.6 \mathrm{~m}$ deep core drilled at the Accumulation area of San Rafael Glacier, the Northern Patagonia Icefield. Bulletin of Glacier Research, 4:59-68. 


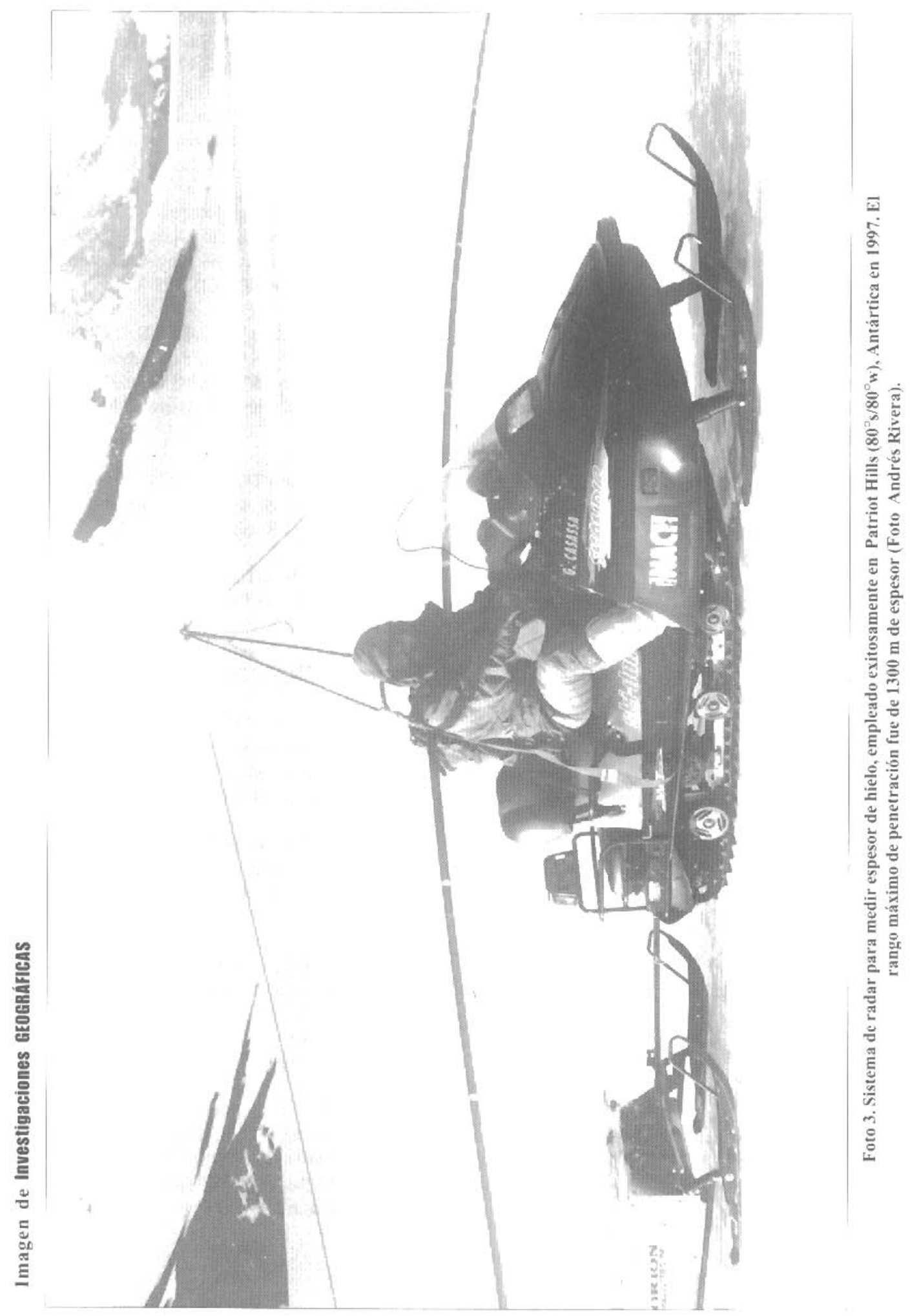

